\title{
Morphology and biological notes of Macrosiagon octomaculata (Gerstaecker) triungulinid and a summary of the knowledge on immature stages of the genus (Ripiphoridae)
}

\author{
Mônica Antunes Ulysséa ${ }^{1,3}$ \& Fabiano Fabian Albertoni', \\ 1 Universidade de São Paulo (USP), Museu de Zoologia (MZUSP). São Paulo, SP, Brasil. \\ 2 ORCID: http://orcid.org/0000-0001-7296-4659. E-mail: monicaulyssea@gmail.com (corresponding author) \\ ${ }^{3}$ ORCID: http://orcid.org/0000-0001-6588-2671. E-mail: fabianoalbertoni@gmail.com
}

\begin{abstract}
Species of Macrosiagon Hentz are known to be wasp and bee parasitoids. Here, we present information on Macrosiagon octomaculata (Gerstaecker, 1855), including eggs and triungulinids, found on Paepalanthus polyanthus (Bong.) Sano (Eriocaulaceae) blooming in restinga habitat on Santa Catarina Island, South Brazil. This is the first record of an Eriocaulaceae species playing an important role in the Macrosiagon bionomics and the first accurate record of Ripiphoridae for southern Brazil, Santa Catarina state. In the study area, P. polyanthus attracted an inordinate number of insect species and one Thynnidae wasp was captured with a triungulinid on its wing. Eggs and triungulinids were also found on one plant of $P$. polyanthus and associated with M. octomaculata. We provide descriptions of the female reproductive organs as well as the morphology of the triungulinid of M. octomaculata. A detailed examination of the triungulinid revealed novelties that complement information from previous publications regarding the Ripiphoridae. We also compare triungulinids of $M$. octomaculata with those of other species, and provide a table summarizing comparative characters. Finally, we provide a table with current information on the recorded host species and immatures of Macrosiagon.
\end{abstract}

Key-Words. Wedge-shaped beetle; Tenebrionoidea; Ripiphorinae; Macrosiagonini; Primary larva; Thynnidae; Eriocaulaceae.

\section{INTRODUCTION}

The Ripiphoridae Gemminger, 1870 is a small family of parasitoid beetles, divided into five subfamilies (Hemirhipidiinae, Pelecotominae, Ptilophorinae, Ripidiinae, and Ripiphorinae), 41 genera, and around 400 species worldwide (Linsley \& MacSwain, 1951; López-Colón, 1997; Falin, 2003; Lawrence et al., 2010; Falin \& Engel, 2014; Barclay, 2015). Adults tend to be fast moving and short-lived as free-living individuals, but the larvae undergo a hypermetamorphic development as endo- and ectoparasites of insects. The larvae of the Pelecotominae and Hemirhipidiinae subfamilies are parasitoids of wood-boring beetles (e.g., Ptinidae and Cerambycidae); Ripiphorinae develop in Hymenoptera nests (e.g., Apidae, Crabronidae, Halictidae, Pompilidae, Scoliidae, Sphecidae, Tiphiidae and Vespidae) and the Ripidiini (Ripidiinae) are parasites of Blattodea. However, the life histories of the Ptilophorinae and Eorhipidiini (Ripidiinae) are completely unknown (Coll, 1942; Linsley \& MacSwain, 1951; Selander, 1991a; López-Colón, 1997; Falin, 2002a; Pinto,
2003; Majka, et al., 2006; Batelka, 2010; Batelka \& Straka, 2011; Batelka et al., 2016).

For Macrosiagon octomaculata (Gerstaecker, 1855) the immature stages are virtually unknown. The only available information with regards to their biology is that they were reared from the cocoons of Campsomeris sp. (Hymenoptera: Scoliidae) (Nowell, 1915) as well as cocoons of Tiphia sp. of several species together (Hymenoptera:Tiphiidae) (Davis, 1919). In this context, this study aims to aggregate information on Macrosiagon octomaculata at both, the species and genus levels, describing the egg, triungulinid and female reproductive organs as well as adding an accurate distributional record to southern Brazil. We also report a wasp species carrying a triungulinid, adult feeding habits, the first record of oviposition on Eriocaulaceae, and compare the first instar larvae with those of other species of Ripiphoridae.

Distribution: Macrosiagon is the most species rich and common genus of Ripiphoridae, with approximately 160 described species (Falin, 2002a, 2004; Batelka, 2010), widely distributed across all 
Table 1. A review of host records and immatures knowledge for Macrosiagon Hentz, 1830, species name alphabetically ordered.

\begin{tabular}{|c|c|c|c|}
\hline Macrosiagon species & Host(s): Family - Species & Immature & Reference(s) \\
\hline M. bifasciata (Marseul, 1877) & $\begin{array}{l}\text { CRABRONIDAE - Cerceris sobo Yasumatsu \& Okabe, } 1936 \\
\text { VESPIDAE - Ancistrocerus fukaianus Schulthess, } 1913 \\
\text { SPHECIDAE - Chalybion japonicum (Gribodo, 1883); Sceliphron deforme (Smith, 1856); } \\
\text { S. madraspatanum (Fabricius, 1781); S. madraspatanum tubifex (Latreille, 1809) }\end{array}$ & Unknown & $\begin{array}{l}\text { Iwata, } 1939 \text { and Kifune, } 1956 \\
\text { (apud Batelka \& Hoehn, 2007) }\end{array}$ \\
\hline $\begin{array}{l}\text { M. bimaculata (Fabricius, 1787) } \\
=\text { M. tricuspidata Lepechin, } 1774\end{array}$ & $\begin{array}{l}\text { MEGACHILIDAE - Megachile } \\
\text { VESPIDAE - Odynerus (uncertain data) }\end{array}$ & $\begin{array}{l}\text { Observed but not described } \\
\text { by Farines; triungulinids } \\
\text { described by Chobaut }\end{array}$ & $\begin{array}{l}\text { Chobaut, 1895, 1906; Farines, } \\
1826\end{array}$ \\
\hline M. cruenta (Germar, 1824) & $\begin{array}{l}\text { VESPIDAE - Pachodynerus nasidens (Latreille, 1817); Ancistrocerus campestris (Saussure, 1852) } \\
\text { SPHECIDAE - Sceliphron caementarium (Drury, 1773) (see further discussion in Snelling 1963); } \\
\text { S. jamaicense (Fabricius, 1775) }\end{array}$ & Unknown & Snelling, 1963; Genaro, 1996 \\
\hline M. cucullata (Macleay, 1887) & SCOLIIDAE - Austroscolia soror (Smith, 1855); Radumeris tasmaniensis (Saussure, 1854) & Triungulinids & $\begin{array}{l}\text { Dodd, 1917; Jarvis, 1922; Elliott, } \\
2011\end{array}$ \\
\hline M. diversiceps (Blackburn, 1899) & CRABRONIDAE - Eating eggs of Pison marginatum Smith, 1856; P. spinolae Schuckard, 1838 & Unknown & Evans et al., 1980; Callan, 1981 \\
\hline M. excavata (Champion, 1891) & SPHECIDAE - Sceliphron assimile (Dahlbom, 1843) & Unknown & Hunt, 1999 \\
\hline $\begin{array}{l}\text { M. ferruginea (Fabricius, 1775) } \\
=\text { M. flabellata (Fabricius, 1781) }\end{array}$ & $\begin{array}{l}\text { VESPIDAE - Euodynerus variegatus (Fabricius, 1793) (= Odynerus crenatus Lepeletier, 1841); } \\
\text { E. disconotatus (Lichtenstein, 1884); Rhynchium oculatum (Fabricius, 1781); Symmorphus } \\
\text { murarius (Linnaeus, 1785) (= Odynerus nidulator Saussure, 1855); Synagris calida (Linnaeus, } \\
\text { 1758); S. sicheiliana Saussure, 1863; S. spiniventris (Illiger, 1802) }\end{array}$ & $\begin{array}{l}\text { Triungulinids and late instars } \\
\text { described }\end{array}$ & $\begin{array}{l}\text { Chobaut, 1891a, b, 1895; } \\
\text { Roubaud, 1910; Bequaert, 1918; } \\
\text { Grandi, 1936; Heitmans et al., } \\
1994\end{array}$ \\
\hline M. flavipennis (LeConte, 1866) & CRABRONIDAE - In cocoon of Bembex spinolae Lepletier, 1845 & Unknown & Barber, 1915; Vaurie, 1955 \\
\hline M. gracilis Manfrini de Brewer, 1966 & $\begin{array}{l}\text { HALICTIDAE - Reared from cells of Megalopta ecuadoria Friese, } 1926 \text { and M. genalis Meade- } \\
\text { Waldo, } 1916\end{array}$ & $\begin{array}{l}\text { Triungulinids were collected, } \\
\text { but not described (Falin, 2004) }\end{array}$ & Falin et al., 2001; Falin, 2004 \\
\hline M. mutilata (Gerstaecker, 1855) & APIDAE - Possibly Exomalopsis similis Cresson, 1865 [= E. globosa (Fabricius, 1793)] & Unknown & $\begin{array}{l}\text { See discussion in Falin, 2004: } \\
\text { p. } 12\end{array}$ \\
\hline M. nasuta (Thunberg, 1784) & $\begin{array}{l}\text { VESPIDAE - Anterhynchium flavomarginatum (Smith, 1852); A. flavomarginatum micado } \\
\text { (Kirsch, 1873); A. flavopunctatum flavopunctatum (Smith, 1852); Discoelius zonalis (Panzer, } \\
\text { 1801); Epsilon manifestatum crassipunctatum (Gusenleitner, 1991); Eumenes fraterculus Dalla- } \\
\text { Torre, 1894; E. micado Cameron, 1904; E. rubrofemoratus Giordani Soika, 1941; Euodynerus } \\
\text { quadrifasciatus (Fabricius, 1793); E. niponicus niponicus (Schulthess, 1908); E. notatus } \\
\text { (Jurine, 1807); Orancistrocerus drewseni Saussure, 1857; Oreumenes decoratus Smith, 1852; } \\
\text { Pararhynchium ornatum (Smith, 1852); Rhynchium haemorrhoidale (Fabricius, 1775) }\end{array}$ & Unknown & $\begin{array}{l}\text { Iwata, 1939; Kifune, 1956; } \\
\text { Matsumoto, } 2002 \text { (apud Batelka } \\
\text { \& Hoehn, 2007); Yamane, } 1990\end{array}$ \\
\hline M. octomaculata (Gerstaecker, 1855) & $\begin{array}{l}\text { SCOLIIDAE - In cocoons of Campsomeris } \\
\text { TIPHIIDAE - In cocoons of Tiphia }\end{array}$ & $\begin{array}{l}\text { Egg and triungulinid described } \\
\text { here }\end{array}$ & Nowell, 1915; Davis, 1919 \\
\hline M. pectinata (Fabricius, 1775) & TIPHIIDAE - Tiphia inornata Say, 1824 & Unknown & $\begin{array}{l}\text { Riley, 1874; Vaurie, 1955; Davis, } \\
1919\end{array}$ \\
\hline M. praeusta (Gebler, 1829) & VESPIDAE - Gymnomerus laevipes (Shuckard, 1837) (= Odynerus laevipes) & Unknown & Chobaut, 1895 \\
\hline M. cf. punctulaticeps (Blackburn, 1899) & $\begin{array}{l}\text { CRABRONIDAE - Found in cocoons of Pison } \\
\text { SPHECIDAE - Chalybion }\end{array}$ & Unknown & Batelka \& Hoehn, 2007 \\
\hline M. punctulaticeps (Blackburn, 1899) & THYNNIDAE - Found in cocoons of different species of Thynninae & Unknown & Smith, 1971 \\
\hline M. pusilla (Gerstaecker, 1855) & $\begin{array}{l}\text { POMPILIDAE - In the cells nest of Auplopus } \\
\text { TIPHIIDAE - In cocoons of Tiphia pullivora Allen \& Jayres, } 1930\end{array}$ & Unknown & $\begin{array}{l}\text { Clausen, 1940; Batelka \& Hoehn, } \\
2007\end{array}$ \\
\hline M. sayi (LeConte, 1858) & THYNNIDAE - In cocoons of Myzinum (= Myzine, = Elis) & Unknown & Rivnay, 1929; Vaurie, 1955 \\
\hline M. semipunctata $($ Lea, 1904) & SPHECIDAE - Sceliphron formosum (Smith, 1856) & Unknown & Callan, 1981 \\
\hline M. vittata (Erichson, 1847) & APIDAE - Pupae in the cells and adults in the nests of Exomalopsis bruesi Cockerell, 1914 & $\begin{array}{l}\text { Pupae were collected, but not } \\
\text { described (Falin, 2004) }\end{array}$ & Rozen, 1997 \\
\hline Macrosiagon sp. & $\begin{array}{l}\text { SPHECIDAE - Sceliphron asiaticum (Linnaeus, 1758) } \\
\text { VESPIDAE - Discoelius zonalis (Panzer, 1801) (= D. japonicus Pérez, 1905); Zeta argillaceum } \\
\text { (Linnaeus, 1758) }\end{array}$ & - & $\begin{array}{l}\text { Yamane, 1990; Hunt, 1999; } \\
\text { Matthews \& González, } 2004\end{array}$ \\
\hline
\end{tabular}

continents, except Antarctica and New Zealand (Falin, 2002a; Batelka, 2004, 2007, 2011b; Lawrence et al., 2010). In the Americas, their northern distributional limit is Ontario, Canada (Tomlin \& Miller, 1989; Campbell, 1991) and their southern limit is Entre Ríos, Argentina (Vaurie, 1955; Manfrini de Brewer, 1966; Falin, 2002b, 2004).

Host insects: Species of this genus are known to parasitize a broad variety of solitary wasps - in the families Crabronidae, Pompilidae, Scoliidae, Sphecidae, Tiphiidae, and Vespidae (Clausen, 1976; Linsley \& MacSwain, 1951; Falin, 2002a; Batelka \& Hoehn, 2007; Lawrence et al., 2010), and rarely bees - in the families Apidae and Halictidae (Clausen, 1976; Tomlin \& Miller, 1989; Falin et al., 2001; Falin, 2002a; Lawrence et al., 2010) (Table 1). A recent study suggested that different species or species complexes of Macrosiagon have host associations with different genera or subfamilies of bees or wasps (Batelka \& Hoehn, 2007). However, the biology of most species remains poorly known (Falin, 2002a; Batelka \& Hoehn, 2007). The hosts of only about $10 \%$ of species have been confirmed (Falin et al., 2001), only a few have had parts of their life cycles described, and most immature stages remain unknown (Falin, 2002a).

Visited and transfer plants: Adults of Macrosiagon are reported as visitors of Amaranthaceae - genera Aerva Forssk. and Sericocomopsis Schinz (Batelka, 2011b); 
Apiaceae - genera Daucus L. and Eryngium L. (Chobaut, 1895, 1906; Coll, 1942; Sánchez Rodriguez, 2001; Falin, 2002b; Cillo et al., 2019); Asteraceae - genera Asclepias L., Aster L., Baccharis L., Eriogonum Michx., Mikania Wild, Pluchea Cass., Senecio L., and Solidago L. (Rivnay, 1929; Linsley \& MacSwain, 1951; Falin, 2002a; Verdugo, 2010); Euphorbiaceae-genus Croton L. andEuphorbiaL.(Batelka, 2011 b); Lamiaceae - genera Hyptis Jacq., Pycnanthemum Michx., Mentha L. and Monarda L. (Chobaut, 1895; Rivnay, 1929; Gobbi, 2002 apud Batelka \& Chaboo, 2015; Sánchez Rodriguez, 2001; Batelka \& Hoehn, 2007; Batelka, 2011b); Resedaceae - Ochradenus Delile (Batelka, 2008c apud Batelka, 2011b); and Rubiaceae - Mitracarpus Zucc. and Spermacoce L. (Batelka, 2011b) (see Batelka, 2011b for discussion on accidental and often visits). The females are known to lay clusters of hundreds of eggs on flowers, the undersides of leaves and other parts of plant, as well as in crevices in the soil near the plant (Jarvis, 1922; Clausen, 1940). These places can be a source of triungulinid infestation of passing bees and/or wasps (Robertson, 1924; Linsley \& MacSwain, 1951). When eggs and triungulinids are observed on plants, these are denominated as 'transfer plants' (sensu Batelka, 2011a). Triungulinids were collected on Eryngium L. (Apiaceae) (Chobaut, 1895, 1906; Farines, 1826).

On a single locality in Laos three adults of Macrosiagon species were collected, presumed on flowers of Castanopsis (L.) (Fagaceae). Usage of the same transfer plant by different Macrosiagon species, once this is confirmed, is maybe possible because each of the recorded ripiphorid species is known to parasitize a different group of hymenopterans (Batelka, 2013).

Biology: After hatching, individuals of Macrosiagon pass through at least two distinct larval stages (host-seeking or phoretic stage and feeding stage), which exhibit completely different biological and morphological traits (hypermetamorphosis). The host-seeking or phoretic stage is characterized by campodeiform first instar larva, known as a triungulinid, which is involved in the ectoparasite phase. The triungulinids attach themselves to adult hymenopteran hosts (Clausen, 1976) using their mandibles to grasp body hairs (Selander, 1991a; Tomlin \& Miller, 1989), or to penetrate soft cuticles and wings (Linsley et al., 1952). The host then transports them into its nest, where they change to the feeding stage. At this point, they enter the bodies of the host larvae and undergo enormous growth through the extension of their intersegmental membranes to assume their new form, named 'repleta' by Grandi (1936). Once the host larva approaches maturity, the pseudoeruciform Macrosiagon larvae emerge from their hosts and continue feeding externally (Grandi, 1936; Clausen, 1976; Selander, 1991a). It is not clear how many larval instars are involved in the whole cycle, nor if the triungulinid molts to the second instar within or externally to the host's body. In the most detailed biological description of a Macrosiagon species, Grandi (1936) did not mention their ecdysis, and did not observe the entire life cycle. Nevertheless, it is believed that Macrosiagon species most likely have six larval in- stars, like other Ripiphoridae, before molting to pupae. The larvae completely consume their hosts before pupating within the host's nest (Selander, 1991a).

\section{Macrosiagon octomaculata (Gerstaecker, 1855)}

Diagnosis: Adults of Macrosiagon octomaculata (Figs. 1-3) can be distinguished from other species of Macrosiagon by the elevated process at the apex of the pronotal disc (Batelka, 2011b); concolorous pronotum and elytra that are yellow or orange with black marks or black with yellow or orange marks (Rivnay, 1929; Linsley \& MacSwain, 1951; Vaurie, 1955); two foremost metatarsomere rounded (Vaurie, 1955); and second metatarsomere thicker and shorter than, or subequal to, the third (Rivnay, 1929; Linsley \& MacSwain, 1951).

Distribution: Widely distributed throughout the Americas with records from the USA (Alabama, Arizona, California, Florida, Georgia, Illinois, Kansas, Missouri, North Carolina, New Mexico, Texas, and Virginia) (Gerstaecker, 1855; LeConte, 1858; Horn, 1875; Rivnay, 1929; Linsley \& MacSwain, 1951), Guatemala (Chamiquin, Chimaltenango, and San Jeronimo), Panama (Chiquiri), Colombia, Guyana (former British Guiana) (Vaurie, 1955), French Guiana (Batelka, 2011b), Brazil (states of Bahia and Pernambuco) (Gerstaecker, 1855), Peru (González \& Juárez, 2016), Paraguay and Argentina (Batelka, 2011b).

\section{MATERIAL AND METHODS}

\section{Study site and associated plant}

Field work was conducted in Brazil, Santa Catarina state, Florianópolis city, Restinga da Joaquina (coastal sand dunes environment), between $27^{\circ} 36^{\prime}$ S and $48^{\circ} 27^{\prime} \mathrm{W}$, from 2007 to 2009. The Restinga da Joaquina comprises a large area of low-lying wetlands situated between two rows of fixed and semi-fixed sand dunes (Scherer \& Castellani, 2004). The vegetation consists predominantly of herbs and shrubs, but a considerable area is devoid of plant life (Figs. 4-5).

The genus Paepalanthus sect. Actinocephalus (Körn.) Ruhland. (Poales: Eriocaulaceae: Paepalanthoideae) consists of 28 species restricted to the open areas of Brazil. Paepalanthus polyanthus is the most widespread and morphologically variable species in the genus (Sano, 2001) with a population at the study site that is characterized by short-lived monocarpic individuals (Castellani et al., 2001) that have a unique fractal-like structure (Figs. 5-6). Most have a central axis from which several scapes arise, each ending in an umbel. Sometimes the axis itself also bears an umbel. Each umbel has around 290 pedicels that terminate in capitula, which in turn consist of about 20 flowers (Castellani \& d'Eça-Neves, 2000), each of which is made-up of numerous stamens and carpels. At the study site, plants tended to grow in non-continuous groups in areas subject to regular flooding (Castellani et al., 1996). 


\section{Sampling and field observations}

Adults of Ripiphoridae were collected on October $2007\left(12^{\text {th }}, 21^{\text {st }}, 23^{\text {rd }}\right.$ and $\left.28^{\text {th }}\right)$ and November 2009. On November $10^{\text {th }}, 2007$, eggs and triungulinids were observed and partially collected, and on $14^{\text {th }}$ one Myzinum sp. (Hymenoptera: Thynnidae: Myzininae) were collected bearing one triungulinid on its right hind wing. All specimens were collected on Paepalanthus polyanthus. Detailed information of the field expeditions and observations are presented in Table 2 in chronological order.

In addition to this, field observations were made on M. octomaculata behavior and on triungulinid behavior. The plant that possessed triungulinids was observed from a distance of two meters between $08: 30$ and 10:30 am on 19 November 2007. Notes of their behavior and any insects that visited the capitula were taken.

\section{Procedures with material}

We made Scanning Electron Micrographs (SEM) of triungulinids at the Universidade Federal de Santa Catarina/UFSC in the Laboratório Central de Microscopia Eletrônica (Central Laboratory of Electronic Microscopy) with a JEOL JSM-6390LV microscope as well as at the Museu de Zoologia da Universidade de São Paulo (MZSP) in the Laboratório de Microscopia Eletrônica with a Carl Zeiss microscope LEO 440. Triungulinids were dehydrated at $50^{\circ} \mathrm{C}$ for 12 hours and coated in gold (four specimens) or carbon (one specimen). We dehydrated a second batch of three specimens to the point of $100 \%$ ethanol. Two of these were coated in gold and one in carbon.

We examined and photographed triungulinids under a Leica DM 5000B optical microscope after treating them first with lactic acid and conducted the same procedure after treating then with $\mathrm{KOH}$ and acetic acid. Each specimen was placed on a slide with Hoyer's solution and a coverslip placed over them. We took photographs and measurements using Leica Application Suite 4.1.0 and made drawings from a Camera Lucida attached to a Zeiss Axioscope at $40 \times$ magnification. All measurements (observed measurement, mean $/ \bar{x}$ and standard deviation/s.d.) are given in millimeters.

All adults were pinned, eggs and triungulinids fixed with $80 \%$ alcohol, a few eggs were retained to await hatching. Most of the material is housed at the Museu de Zoologia da Universidade de São Paulo/MZSP, one specimen is housed at Universidade Federal de Santa Catarina/ UFSC. Morphological nomenclature for Coleoptera follows Grandi (1936), Tomlin \& Miller (1989), Pohl \& Beutel (2004), and Batelka et al. (2019a). Morphological nomenclature for Paepalanthus polyanthus follows Sano (2001).

\section{Identifications}

Once collected, family and genera were defined by sight by authors. We identified all adult specimens of Ripiphoridae using the key provided by Linsley \&
MacSwain (1951). These were confirmed by Zachary $\mathrm{H}$. Falin, from the Natural History Museum of University of Kansas. Wasp identifications were made using the key presented by Fernández \& Sharkey (2006) and confirmed by Lynn S. Kimsey from the University of California. Classification of Paepalanthus polyanthus within Eriocaulaceae was based on Andrade et al. (2010).

Considering the abundance of Macrosiagon octomaculata observed and collected on P. polyanthus and the absence of any other species in any of the samples, we assumed that all the triungulinids collected belonged to M. octomaculata.
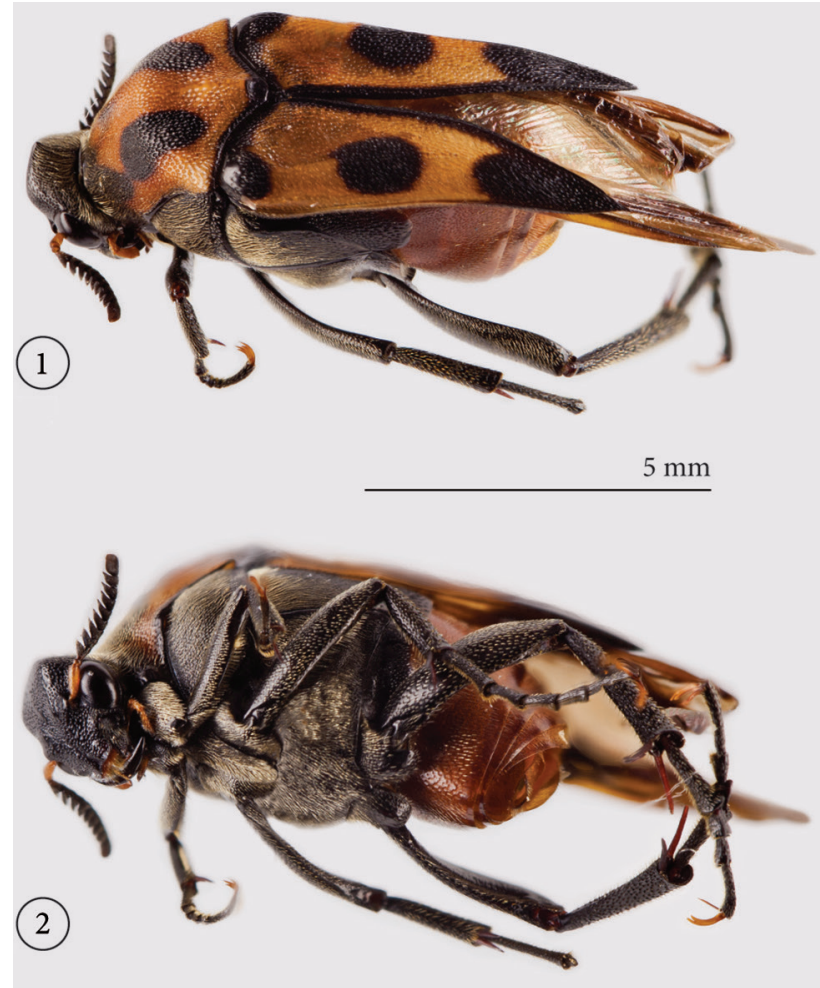

(2)

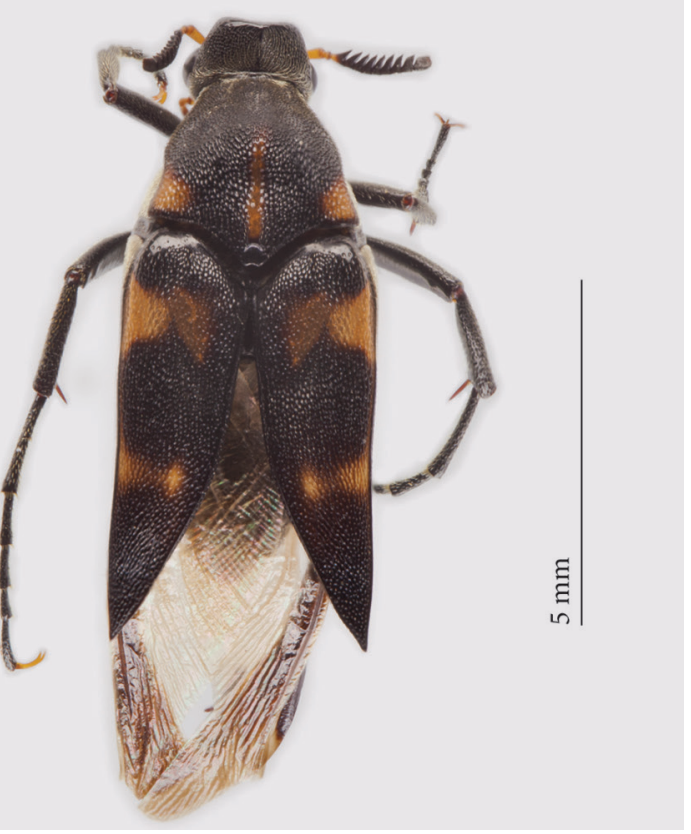

Figures 1-3. Macrosiagon octomaculata (Gerstaecker, 1855) adult female habitus: two phenotypes. (1) dorso-lateral; (2) ventro-lateral; (3) dorsal. 
Table 2. Field expeditions and their consequent results.

\begin{tabular}{cl}
\hline Field expedtions & \\
\hline 19 and 26.vii.2007 & Around 10 hours on field for each expedition. Active searching, sweeping of vegetation and beating tray under few shrubs. No Ripiphoridae collected. \\
12.x.2007 & One female Macrosiagon octomaculata collected by research fellows on Paepalanthus polyanthus. \\
19.x.2007 & No M. octomaculata seen (1 hour searching). \\
21.x.2007 & One female M. octomaculata collected on P. polyanthus. \\
23.x.2007 & Five adults observed. Two females collected. Three resting on the base capitula scape or on bracts (Fig. 77), and 2 actively feeding on capitulum (5 hours searching). \\
24.x.2009 & One adult female of Scotaena sp. (Thynnidae: Scotaeninae) and one adult male of Scotaenini indet. (Thynnidae) on P. polyanthus. \\
26.x.2009 & One adult male of Scotaenini indet. on P. polyanthus. \\
28.x.2007 & Two adults observed. One female dead collected on bract (4 hours searching). \\
10.xi.2007 & More than 300 eggs were found on the base of capitula scape of one umbel (Figs. 73-74). A small amount of eggs (around 120) were collected with a plastic pot (2:30 \\
14.xi.2007 & hours searching). \\
& Triungulinids observed very active among capitula of two umbels. \\
One Myzinum sp. collected bearing one triungulinid on its right hind wing (Figs. 81-83) (3 hours searching). \\
20.xi.2007 & Active searching, sweeping of vegetation and beating tray under few shrubs. No adult Ripiphoridae collected. Around 10 hours on field. \\
19.xi.2007 & Active searching, sweeping of vegetation and beating tray under few shrubs. No Ripiphoridae collected. Around 10 hours on field \\
& Triungulinids observed very active among capitula, although, there were plainly fewer individuals than on 14.xi.2007 (3 hours searching). \\
Two hours of observation in front of the plant, but no wasp visited any of the umbels. One Myzinum sp. collected on P. polyanthus. \\
11 field expeditions between & One female of M. octomaculata observed on P. polyanthus for few minutes (26.xi.2009) (Figs. 78-79). \\
09.x-29.xi.2009 & More than 60 P. polyanthus plants were generally checked, but no M. octomaculata observed. \\
\hline
\end{tabular}

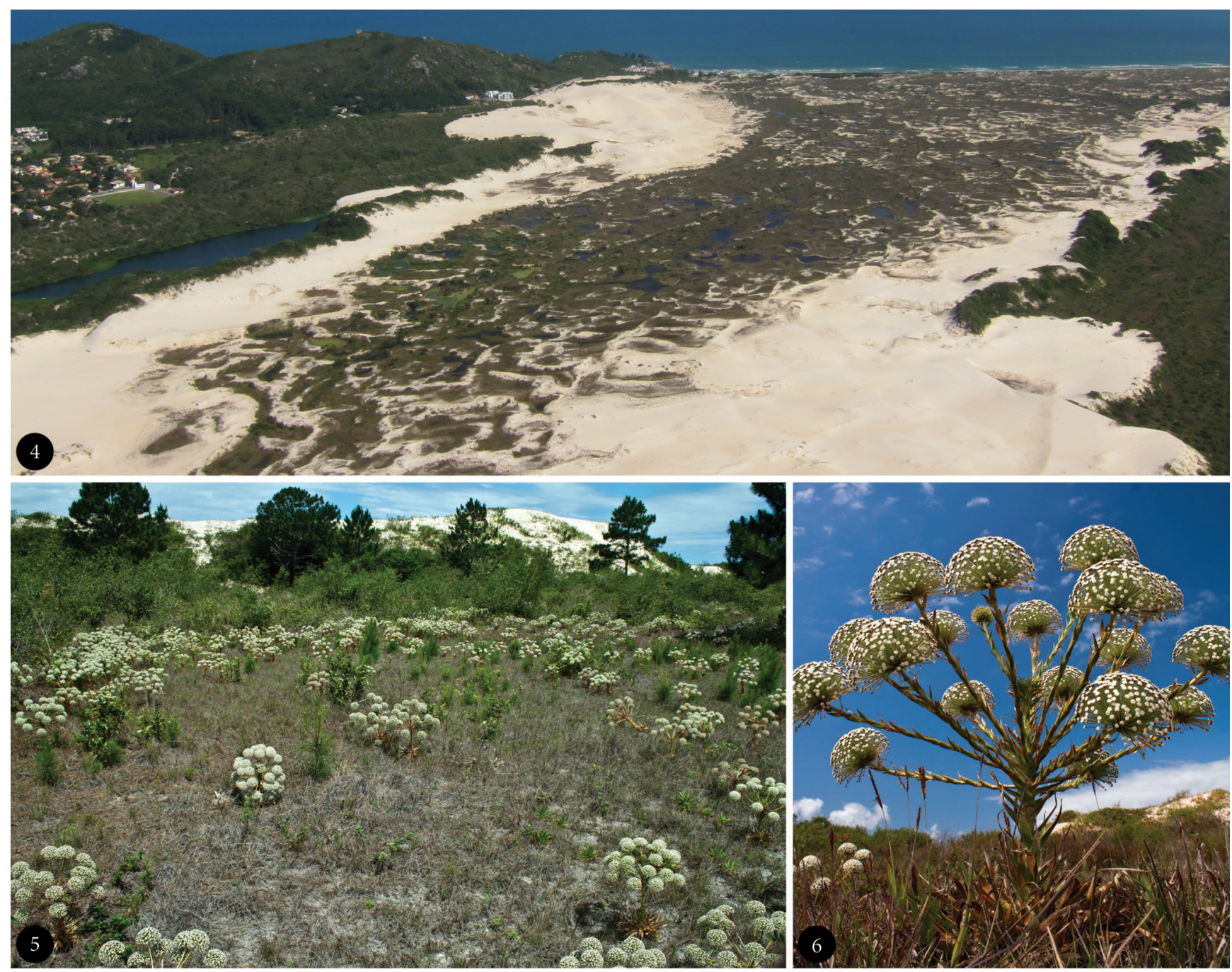

Figures 4-6. Collecting area at restinga and host plant Paepalanthus polyanthus (Bong.) Sano on Santa Catarina Island. (4) aerial view of the collection locality (photo: André Vieira da Rosa); (5) cluster of P. polyanthus; (6) one entire plant depicting its general morphological structures, central axis, umbels, scapes and capitula. 


\section{RESULTS}

\section{Macrosiagon octomaculata (Gerstaecker, 1855)}

(Figs. 1-3, 7-69, 73-83)

Material examined: Macrosiagon octomaculata (Coleoptera: Ripiphoridae): BRAZIL, Santa Catarina, Florianópolis, Restinga da Joaquina, on Paepalanthus polyanthus, 12.x.2007, E.L. Galitizk leg., one adult (MZSP 31312); 21.x.2007, M.A. Ulysséa leg., one adult (MZSP 31313); 23.x.2007, F.F. Albertoni \& A.G. Martins leg., two adults (MZSP 31314, 31315); 28.x.2007, F.F. Albertoni \& A.G. Martins leg., one adult (MZSP 31316);, 10.xi.2007, F.F. Albertoni \& C.E. de Siqueira leg., 75 eggs and 45 triungulinids (MZSP 10368); 26.xi.2009, A.G. Martins leg., one adult (UFSC). Myzinum sp. (Hymenoptera: Thynnidae: Myzininae): BRAZIL, Santa Catarina, Florianópolis, Restinga da Joaquina, on Paepalanthus polyanthus: one female adult with triungulinid on the right hind wing (MZSP 31366).

Taxonomic issues: Gerstaecker (1855) described M. octomaculata (written as M. 8 maculatus) and its three varieties: a, b and c. Later, Horn (1875) considered Macrosiagon sayi (LeConte, 1858) and Macrosiagon puncticeps (LeConte, 1858) as variants of M. octomaculata mostly based on similarities in color. Rivnay (1929) revalidated $M$. sayi, but retained $M$. puncticeps as a synonym of M. octomaculata and described a new variation of M. octomaculata, var. maritima Rivnay, 1929 (originally written maritimum), currently considered a synonym of $M$. octomaculata (Poole \& Gentili, 1996). Linsley \& MacSwain (1951) validated $M$. octomaculata and $M$. sayi as different species but argued that the last two and $M$. pectinata may be involved in a species complex. Batelka (2011b) recognized nine species groups within Macrosiagon; M. octomaculata species group is formed only by M. octomaculata and M. ukereweana Schilder, 1923.

Due to this long and controversial discussion about the phenotypic differences between species and the possible existence of a species complex, we opted to present adult morphological characteristics and describe part of the female reproductive organs in order to characterize more accurately the specimens we studied to enable future comparisons.

\section{Female characterization and description of reproductive organs (Figs. 1-3, 7-17)}

Six specimens analyzed: Body size varied considerably, from 6.4 to $9.1 \mathrm{~mm}$ (from head to apex of elytra).

Color: Head, sternites of thorax and legs black; antennae with the first two antennomeres and the proximal region of third yellowish, remaining antennomeres black; abdomen black (four individuals) or reddish (two individuals); scutellum black. General body color was not identical in any specimens, Figs. 7-10 illustrate four patterns of dorsal color of pronotum and elytra. Specimens varied from having most of the dorsal surface light brown in color, to most of it darkish to black (Figs. 7-10).

Head: frontal surface and lateral to eyes with no setae, but punctated, area below eyes (gena) and vertex covered with bright setae; one longitudinal smooth stripe from middle of head to vertex. Clypeus slightly invaginated and with a triangular depression medially. Labrum densely covered with bright setae. Mandibles covered with bright setae on proximal area of external sides.
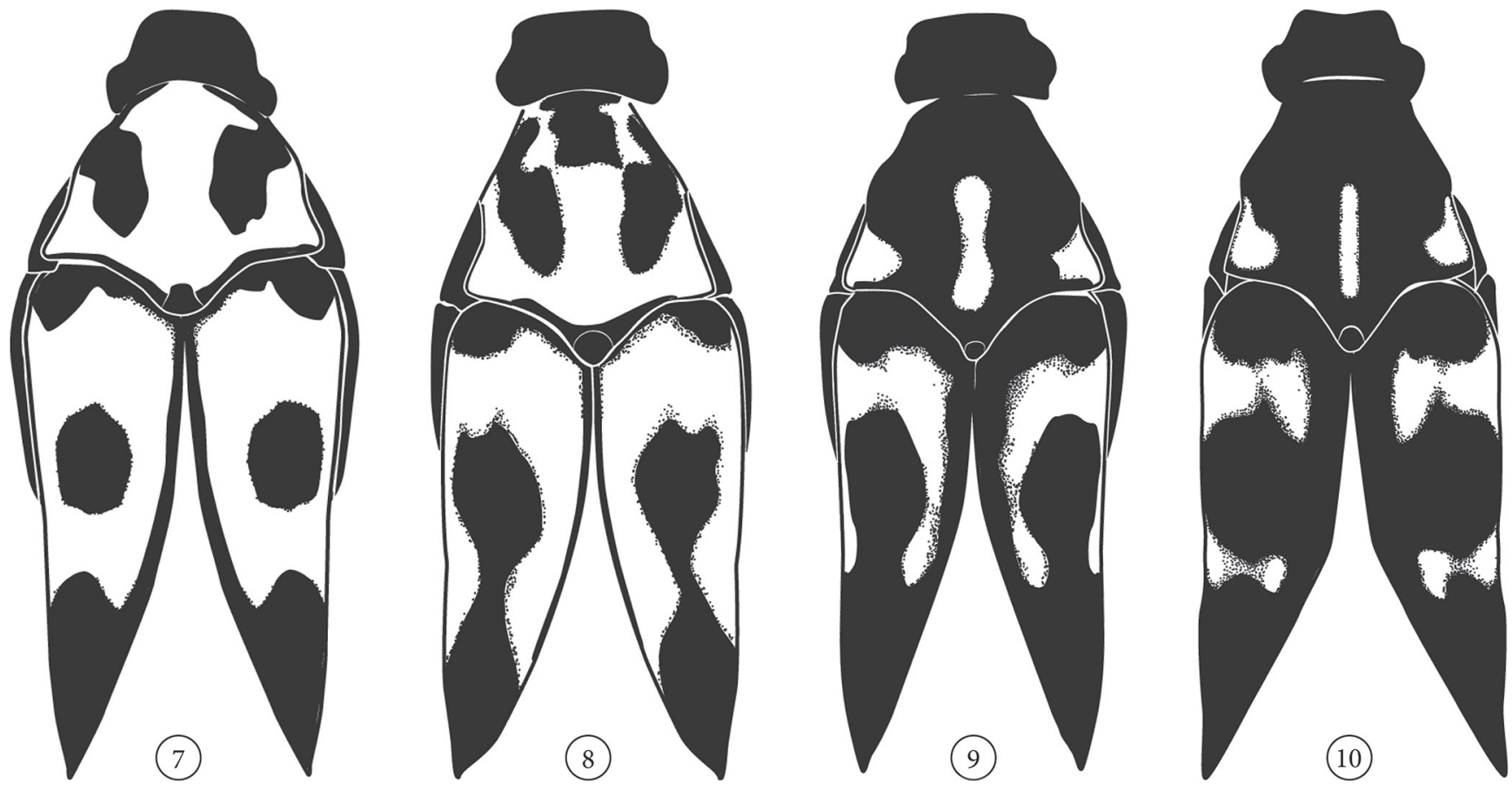

Figures 7-10. Macrosiagon octomaculata (Gerstaecker, 1855) female adult. Dorsal color patterns of pronotum and elytra of four specimens. Black areas are black colored in the specimens and white areas are light brown, as in Figures 1 and 3. From (7) to (10) shows lighter to darker specimens. 
Antennae: 11 antennomeres, antennomere I the longest, antennomere II the shortest, antennomeres III-X pectinate, antennomere XI cuneiform but with rounded apex.

Thorax: Pronotum punctated and covered with bright setae, denser and longer setae anteriorly, short or absent posteriorly; medially with longitudinal and elevated process abruptly ending near posterior margin of pronotal disc; area after process always black; if pronotum and elytra are in their natural and adjacent position, the scutellum is barely visible; thoracic sternites punctated and together with the legs covered by bright setae. Elytra punctated, if bearing setae, then strongly reduced; umbo smooth; one transverse depression on each elytron, directed from umbo to elytral suture.

Abdomen: Sternites VIII and IX, and tergite VIII, internal. Sternite VIII smooth, thin and long, slightly bulged prox-

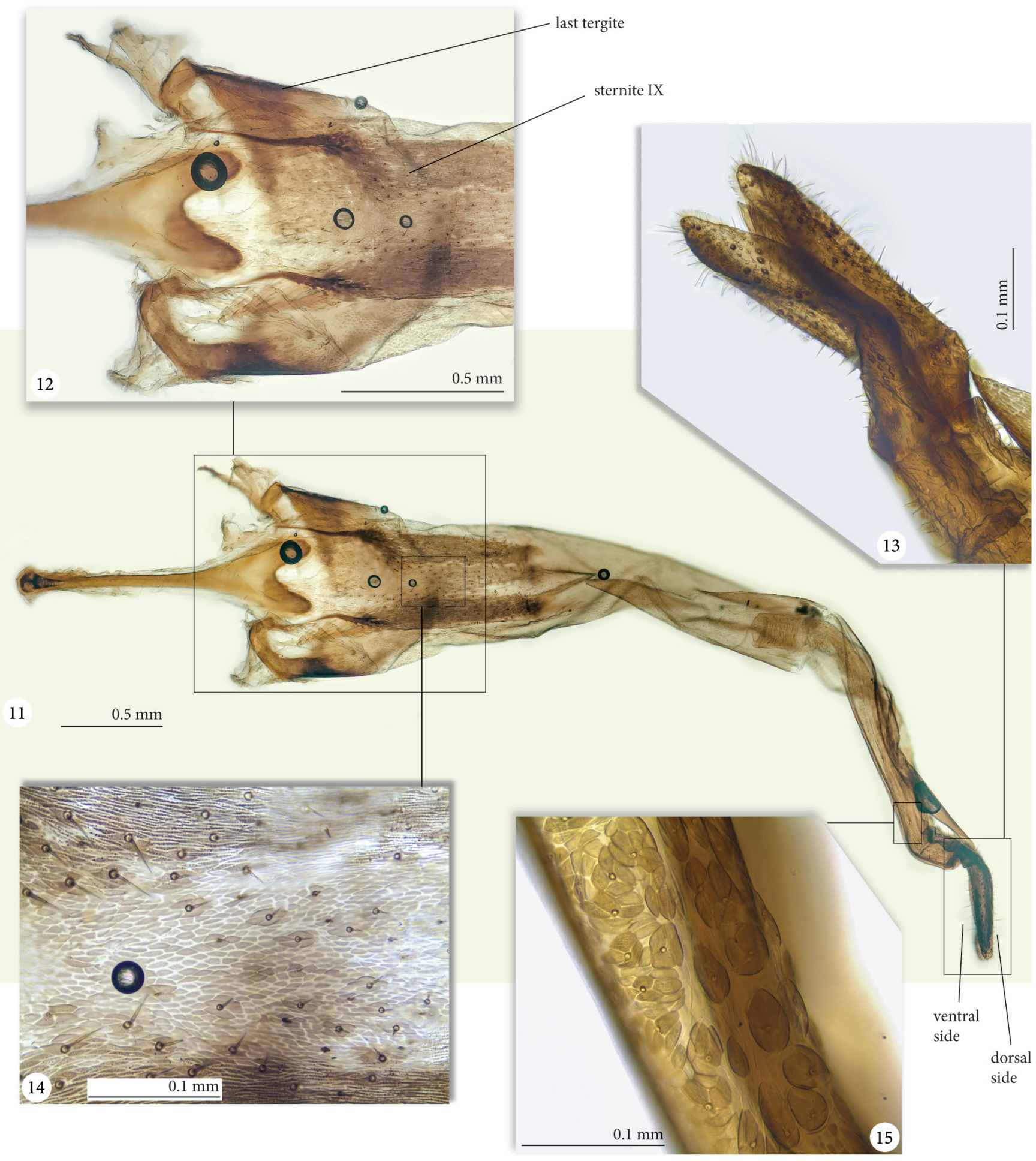

Figures 11-15. Macrosiagon octomaculata (Gerstaecker, 1855) female reproductive organs. (11) sternite VIII and last tergite, with sternite IX and ovipositor extroverted outwards; (12) part of sternite VII, sternite IX with short setae, and last tergite; (13) distal part of ovipositor, dorsal; (14) internal surface of sternite IX; (15) surface near proximal part of ovipositor with sensilla associated with large compartment chambers. 
imally (spiculum gastrale region) and medially invaginated distally (Figs. 11-12, 17); sternite IX bearing many short setae (Fig. 14), integument soft, mostly membranous, each side with a more sclerotized area from which originates a sclerotized, sharp filet, extending proximally (Figs. 11-12, 17). Tergite VIII relatively sclerotized laterally. Ovipositor bearing many short setae associated with glands (Fig. 15); distally the most sclerotized part (gonopore), bearing setae of different sizes and a fringe of setae on the apical border (Fig. 13).

\section{Egg description (Figs. 35, 73-74)}

Eggs were collected with the embryo completely formed, as pharate triungulinids. Although the color observed, dark brown to black, was mostly the embryo colorsome of them were more yellowish; elliptical, about three times as long as wide; ultrastructure (SEM images) of egg surface smooth.

\section{Description of the free-living first instar larva - triungulinid (Figs. 18-69, 73-76, 81-83)}

Body: All measurements are given in millimeters. Length $0.518-0.55(\bar{x}=0.537$, s.d. $=0.01)$, width 0.172-0.183 $(\bar{x}=0.178$, s.d. $=0.003)$; dark brown to black; heavily sclerotized, elongate, elliptical, widest across metathorax, abdomen narrowed apically; tegument transversally, finely and irregularly striated, except for mouthparts, antennae, tibiae, tarsi, and abdominal appendage; with one pair of very long setae on ninth abdominal segment and one pair of median setae on the eighth segment.

Head (Figs. 18-20, 22, 32-34, 36-39, 49-55): head width 0.132-0.149 $(\bar{x}=0.138$, s.d. $=0.005)$, head length 0.108-0.123 ( $\bar{x}=0.116$, s.d. $=0.004)$; prognathous, subtriangular, wider than long, rounded anteriorly, with median longitudinal dorsal line extending to first third of head. Epicranial and frontal sutures absent, but a deep longitudinal median line from labrum to just after $1^{\text {st }}$ third of the head. Clypeus and frons fused. Five stemmata unequal in size, positioned latero posteriorly on each side of the head, behind antennal foramina, in a highly pigmented area; three stemmata positioned latero-dorsally, and two latero-ventrally. Most microsetae represented as dots on Figs. 18-21, under optical microscope resembling pores in magnification lower than $1000 \times$.

Head chaetotaxy: dorsal surface with three pairs of setae (st 1-3) - one pair anteriorly near labrum, one laterally and one longer latero-posteriorly behind stemmata; and numerous microsetae - two/three anteriorly, in each side of median longitudinal line, four medially forming an arcline, two central-posteriorly, and two pairs near the stemmata. Labrum bearing one pair of short setae and, within a slight concavity, one pair of longer setae, each one between two sensilla (red semi-circle on Figs. 52, 54). Stipes anteriorly bearing a long seta contiguous to one microseta. Palpifer with one microseta at middle. Mala with one microseta, one medium seta contiguous to one microseta and a pair of peg-like setae distally. First maxillary palpomere with one pore distally, $3^{\text {rd }}$ palpomere with one pore near base. Some specimens lack one or two dorsal microsetae (such as in Fig. 34, black arrow).

Antennae (Figs. 18-20, 22, 32-34, 36, 38, 40-47, 49-50): length $0.128-0.147$ ( $\bar{x}=0.137$, s.d. $=0.00002, \mathrm{n}=13$ ); located laterally and subposteriorly on head, anteriorly to stemmata, slender, with three antennomeres, as long as head length or longer; antennomere I short, length $0.006-0.008(\bar{x}=0.007$, s.d. $=0.0007)$, wider than long; antennomere II longer than wide, length $=0.050-0.056$ $(\bar{x}=0.053$, s.d. $=0.001, \mathrm{n}=15)$, dorsal margin continuous and slightly curved with a circular sensorial pit near base, ventral margin double narrowed from second third to apex, the enlarged first third bearing a sensorium (S) and one spiniform projection (spin. pro.) laterally; antennomere III whip-like, length $0.072-0.083(\bar{x}=0.076$, s.d. $=0.00002, \mathrm{n}=13$ ) ca. $1.5 \times$ as long as second. Antennal foramina opened ventrally (Fig. 44) and partially enfolding antennomere I.

Mouthparts (Figs. 19-20, 33, 49-55): postgenae delimited by well-defined subgenal suture and hypostomal suture. Labrum divided by a thin longitudinal suture, invaginated medially (Figs. 18, 20, 36, 38-39, 50-54). Mandibles
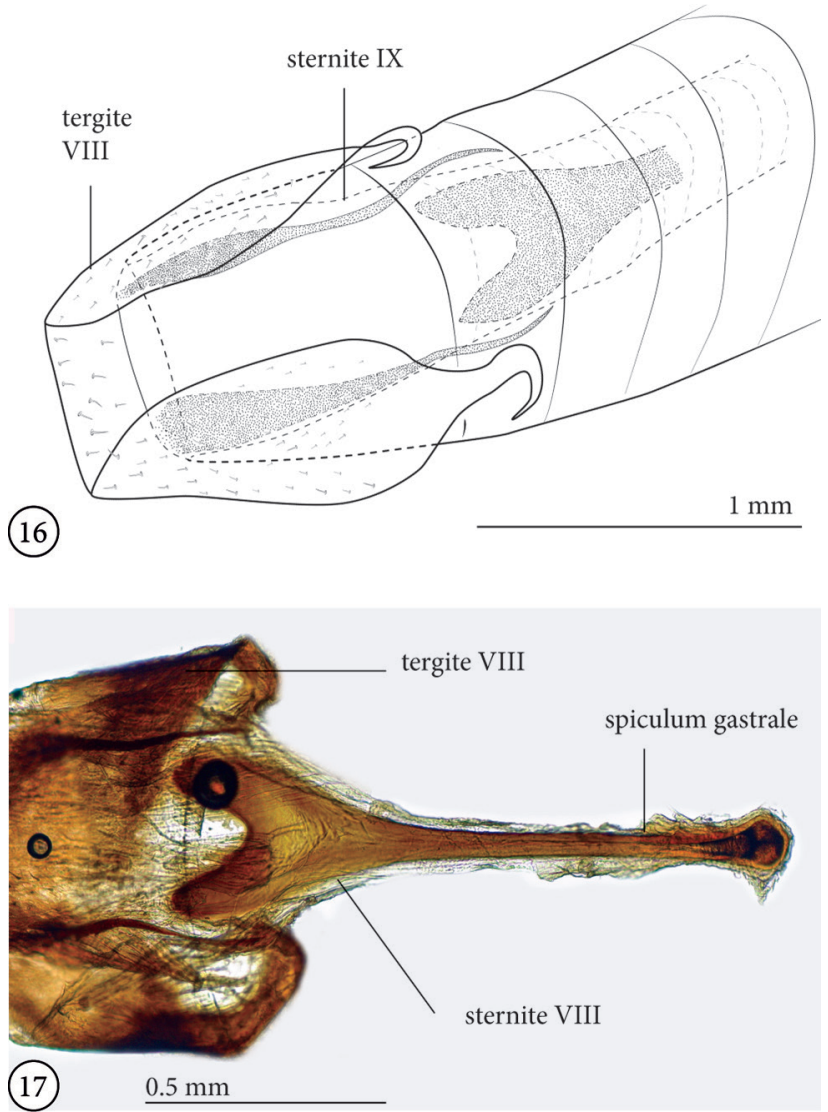

Figures 16-17. Macrosiagon octomaculata (Gerstaecker, 1855) female terminal abdominal segments. (16) position at resting of tergite and sternite VIII and IX, ventral; (17) part of last tergite and sternite VIII, dorsal. 
falciform, covered by head, strongly overlapping each other when closed, inner margin without teeth or toothlike ridges, one pore-like sensillum near condyle on external margin and one on ventral surface (Fig. 52, red arrows), ventral surface irregular; condyle well developed; dorsal surface not examined. Maxillae weakly sclerotized and widened posteriorly; cardo and stipes not fused; car- do narrow and rectangular; stipes longer than wider and dilated basally. Maxillary palpi 3-articulated; first wider than long; second longer than wide, almost twice the length of the first palpomere; third palpomere slightly longer than second, with one lateral digitiform sensillum concealed in a groove on each side (Fig. 54, red arrow). Labium with postmentum almost twice as long as wide,

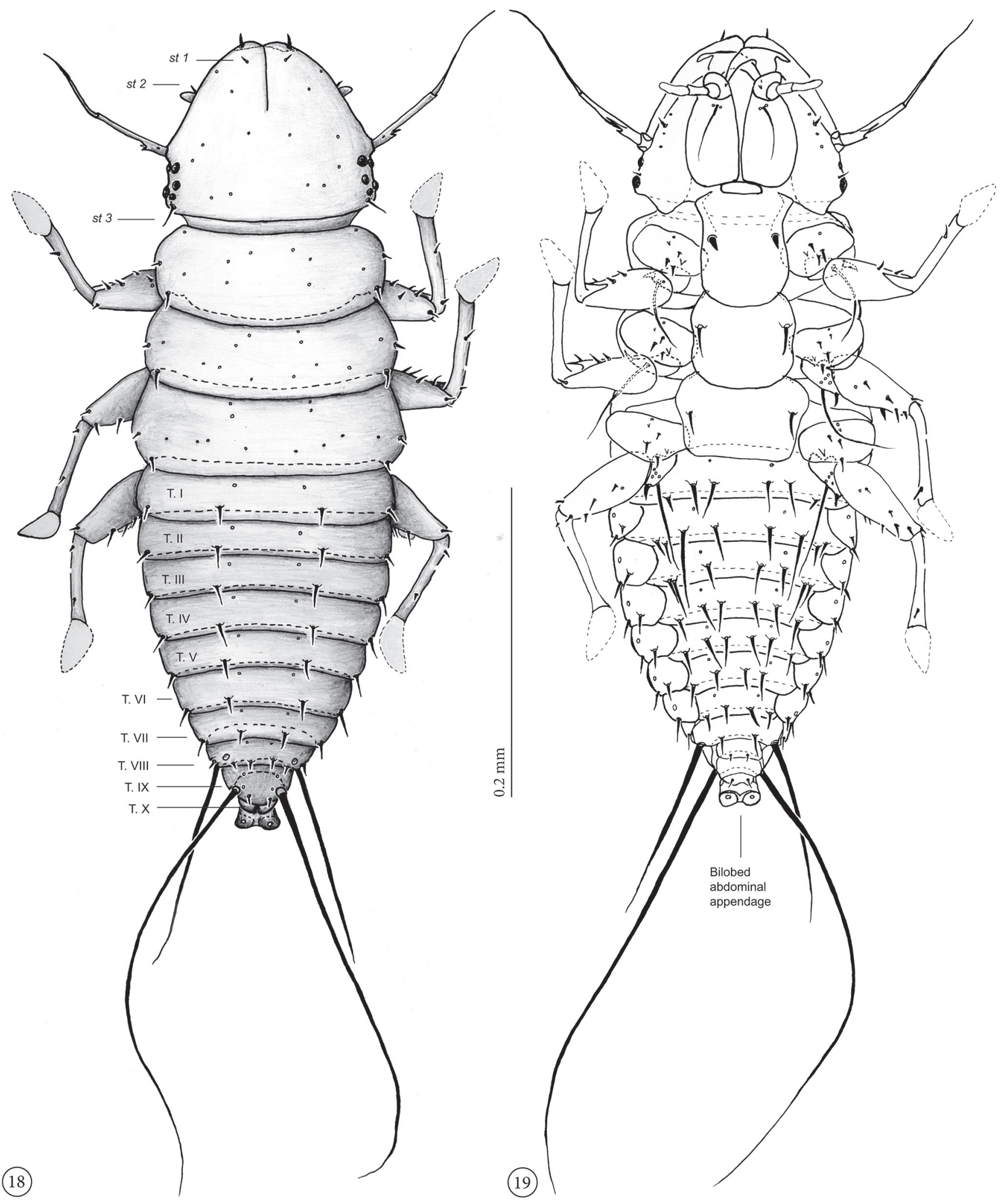

Figures 18-19. Macrosiagon octomaculata (Gerstaecker, 1855) triungulinid habitus and chaetotaxy. (18) dorsal; (19) ventral. T. I to T. IX - Tergites I to IX. 
surface smooth, prementum not observed, apparently reduced to a small membranous region.

Thorax (Figs. 18-19, 22-23, 27-29, 32-34, 50, 56-57): length $0.158-0.169(\bar{x}=0.163$, s.d. $=0.003)$; prothorax length $0.058-0.064(\bar{x}=0.062$, s.d. $=0.003)$; metathorax width $0.172-0.183(\bar{x}=0.178$, s.d. $=0.003)$. About $0.3 \times$ as long as body and $1.4 \times$ as long as head; thoracic segments about equal size, but prothorax slightly longer, metathorax the widest. Spiracles on the pleura of each thoracic segment. Prosternum, mesoventrite and metaventrite consisting of well-developed plates (in Figs. 27-29, 57, pros-plt, mes-plt, met-plt), prosternal plate the narrowest and longest, metasternal plate the widest.

Thoracic chaetotaxy (Figs. 18-19, 22-23, 27-30, 32-33): dorsal surface with numerous microsetae and two pairs of setae near lateral margins of each segment, one pair at middle and one posteriorly. Prosternum bearing one pair of short and stout setae near each lateral margin (Fig. 57, red arrow); meso- and metaventrite laterally each bearing one long seta on each side. Coxal surface with six setae and two pores. Trochanter with four pores, three on a row and one apical, one apical spur and one long seta, slightly longer than femora. Femur bearing several sparse setae. Tibia with three setae on anterior margin, one seta on posterior margin, and one pore on outer face.

Legs (Figs. 18-19, 22, 24, 26, 30-33, 56-65, 67): left segments measured. Foreleg $\bar{x}=0.186, \mathrm{n}=13$; median leg $\bar{x}=0.19, \mathrm{n}=15$; hind leg $\bar{x}=0.20, \mathrm{n}=14$. Frontal trochanter $\bar{x}=0.089$, median trochanter $\bar{x}=0.097$, hind trochanter $\bar{x}=0.102$. Frontal femur $\bar{x}=0.062$, median femur $\bar{x}=0.064$, hind femur $\bar{x}=0.070$. All legs subequal in length. Coxa wider than long; hind coxa widely separated, distance between them subequal to twice the coxal width (Fig. 61). Trochanter subtriangular. Femora slightly shorter than tibio-tarsi, increasing in length from fore to hind leg. Median and hind femura with a denticulate keel distally on inner face (Figs. 58-59, red arrow). Tibia with a longitudinal depression on external face (Fig. 58, red arrow). Pretarsus membranous, pad-like, without claws.

Abdomen (Figs. 18-19, 22, 24-25, 32-33, 66-69): length $0.235-0.261, \bar{x}=0.246$, s.d. $=0.008$. Elongate, gradually attenuated from base to apex, segments I to IX wider than long, $\mathrm{X}$ subquadrate, slightly wider than long, bearing a bilobate appendage. Lateral spiracles on segments I-VII, the largest located dorsally on segment VIII.

Abdominal chaetotaxy (Figs. 18-19, 21-22, 24-25, 32-33, 57, 66-69): tergites I-VII bearing one pair of microsetae anteriorly positioned, one pair of postero-medium setae and one pair of postero-lateral setae; tergites III-VII besides anterior setae, with one pair of postero-medium setae on the ventralized face of tergites; tergite VIII with two pairs of postero-medium setae and one pair of postero-lateral setae, all setae shorter than those on tergites I-VII; tergite IX about $1 / 4$ as wide as tergite I, with one pair of microsetae anteriorly positioned, one pair of posterior short setae and one pair of long setae (maximum length 0.371 ) located postero-laterally, about $0.7 \times$ as long as body. Sternites I, IV-VI with four pairs of setae: one pair of microsetae anteriorly, two pairs of medial setae cen-

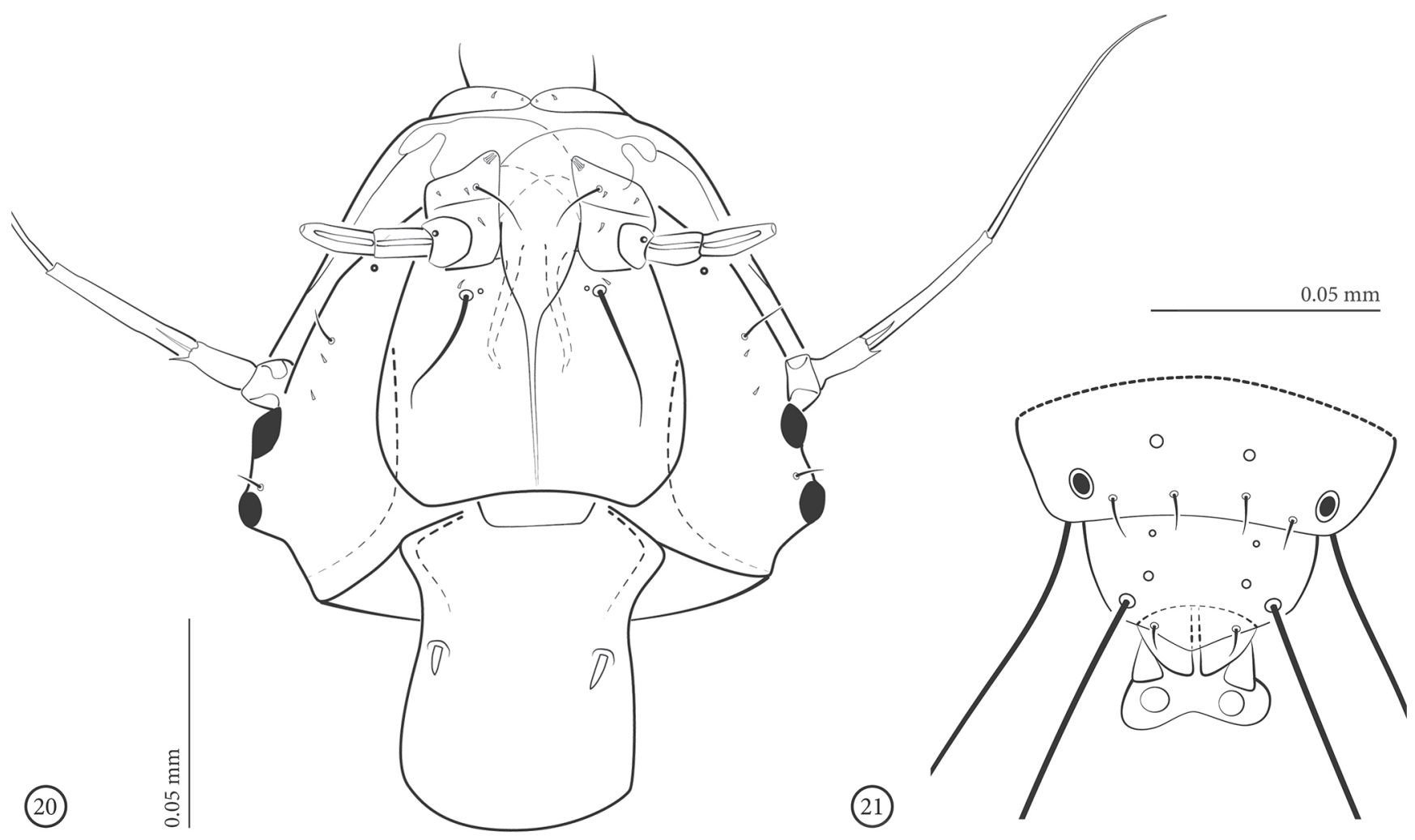

Figures 20-21. Macrosiagon octomaculata (Gerstaecker, 1855) triungulinid. (20) head, ventral; (21) last abdominal tergites and abdominal appendage. 
tral-posteriorly and one pair of lateral setae posteriorly; sternites II-III same configuration, but with two (against one) pairs of lateral setae posteriorly; sternite VII the same as I, but with one (against two) pair of medial setae central-posteriorly; VIII with one pair of microsetae anteriorly positioned, one pair of medial setae and one pair of long lateral setae; IX with one pair of medial and one pair of lateral setae; $X$ with one pair of lateral setae. In some spec- imens, one or two ventral setae absent, especially on segments I, III and VI (setal socket or alveolus missing).

\section{Biological notes}

Macrosiagon octomaculata collected in Restinga da Joaquina, Santa Catarina state, represents the first accu-
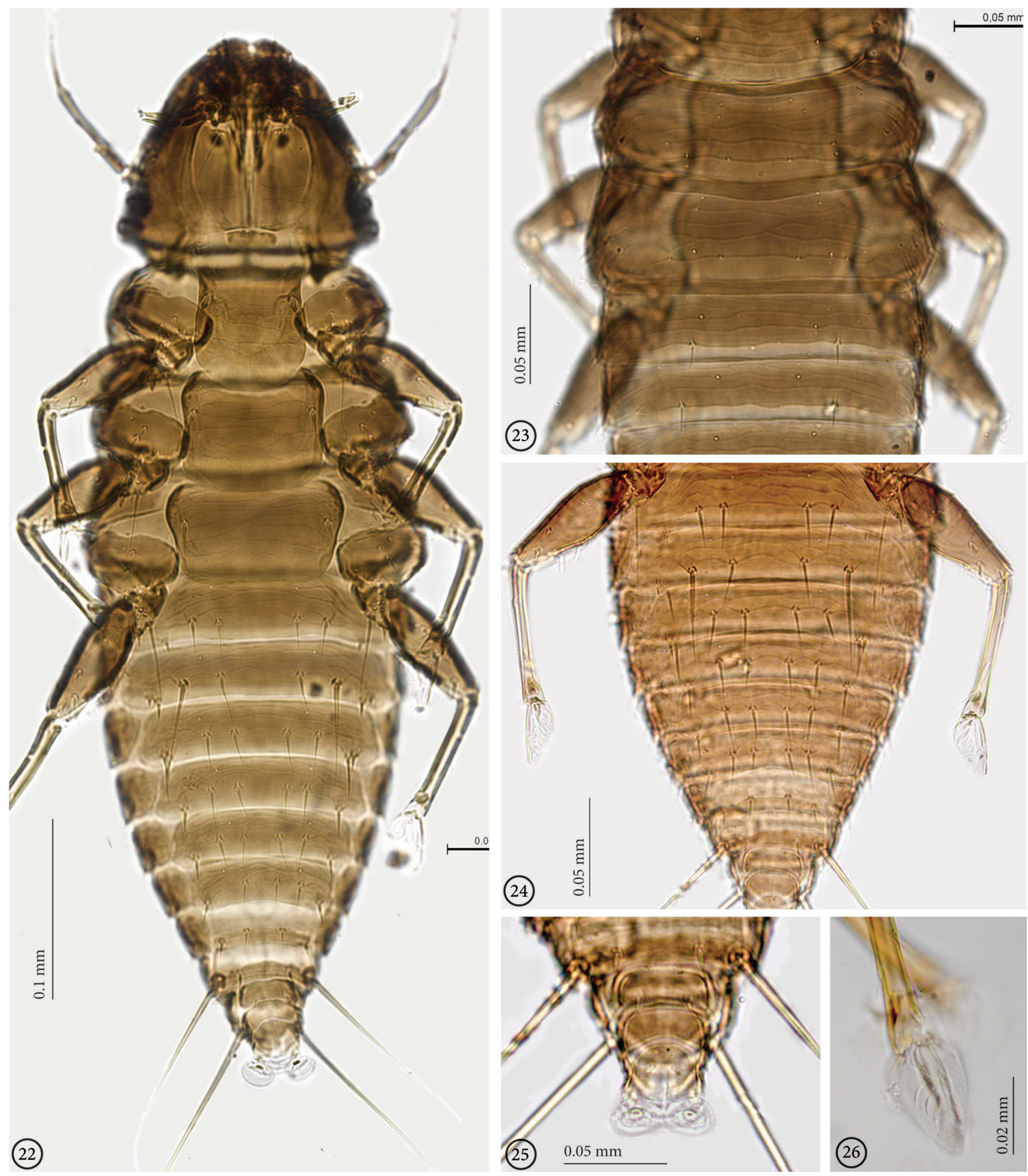

Figures 22-26. Macrosiagon octomaculata (Gerstaecker, 1855) triungulinid. Optical microscope photograph. (22-26) triungulinid treated with acetic acid: (22) ventral habitus; (23) thorax and part of abdomen, dorsal; (24) abdomen and posterior legs, ventral; (25) apex of abdomen with abdominal appendage, ventral; (26) pad-like pretarsus, dorsal. 
rate record for southern Brazil. Collecting information is summarized on Table 2.

Five adults of Ripiphoridae were collected on October $2007\left(12^{\text {th }}, 21^{\text {st }}, 23^{\text {rd }}\right.$ and $\left.28^{\text {th }}\right)$ and November 2009. In November 2007 we located a cluster of eggs and recently hatched triungulinids on a Paepalanthus polyanthus umbel, from which we collected 75 eggs and 45 triungulin-
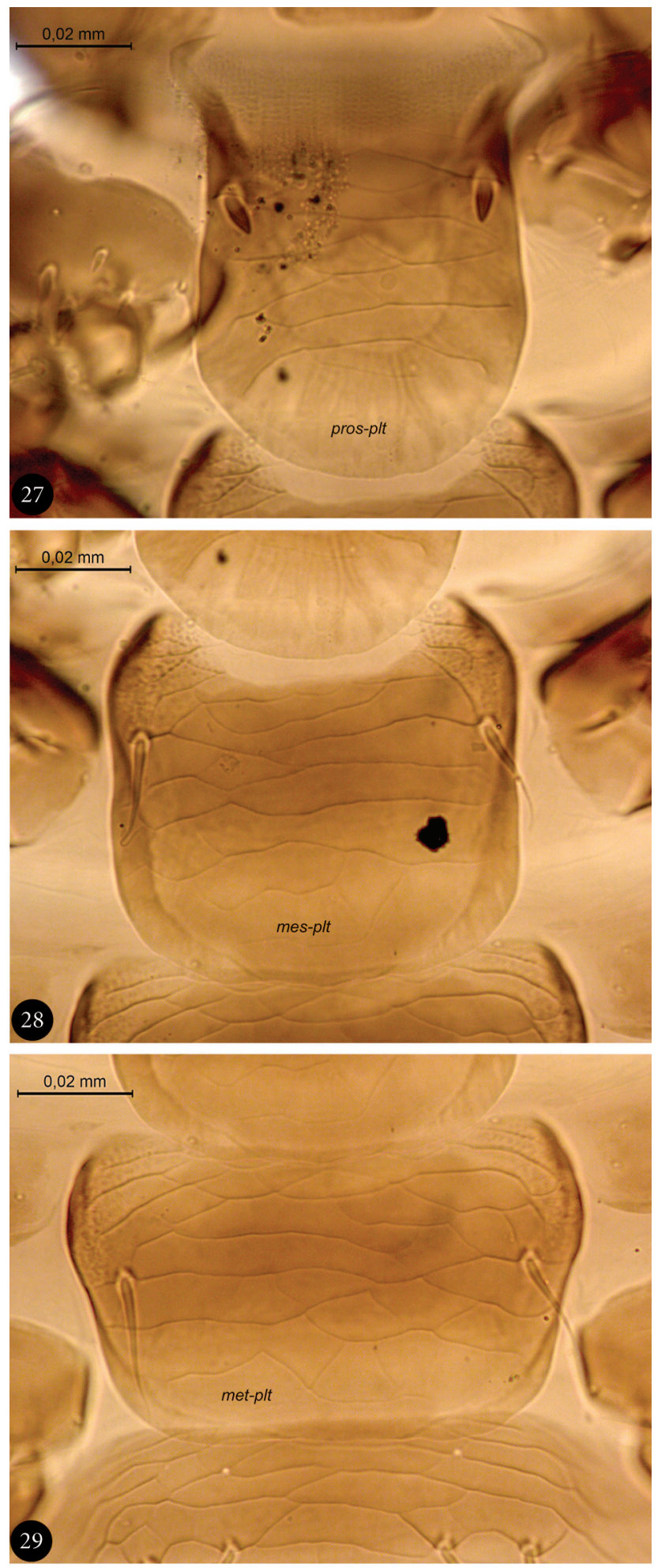

Figures 27-29. Macrosiagon octomaculata (Gerstaecker, 1855) triungulinid. Optical microscope photograph. Thorax. (27) prosternum, pros-plt - prosternal plate; (28) mesosternum, mes-plt - mesosternal plate; (29) metasternum, met-plt - metasternal plate. ids. Most the triungulinids later hatched in the laboratory. Eggs were laid between the bases of the pedicels of a single umbel (Figs. 73-74, eggs with pharate larva) and, when they were found, the capitula did not contain any active triungulinids. However, on hatching, the triungulinids were very active and occupied the capitula of the two neighboring umbels four days after being discovered (Figs. 75-76). This is the first record of Ripiphoridae oviposition on a species of Eriocaulaceae.

Ripiphoridae beetles are known to be short-lived as adults (Batelka, 2013). This was corroborated in this study as adults were only found during a short period within the duration of field work. Nine specimens were found resting on P. polyanthus (Fig. 77) and one was found dead on a bract, whilst the reared individuals lived for only two days.

During the behavioral observation of the triungulinids, most stayed hidden among the tiny flowers of each capitulum but when the umbel was touched would hastily emerge and head towards the most apical parts of the flowers, namely the apex of the filets and styles. Interestingly, they were somehow able to distinguish
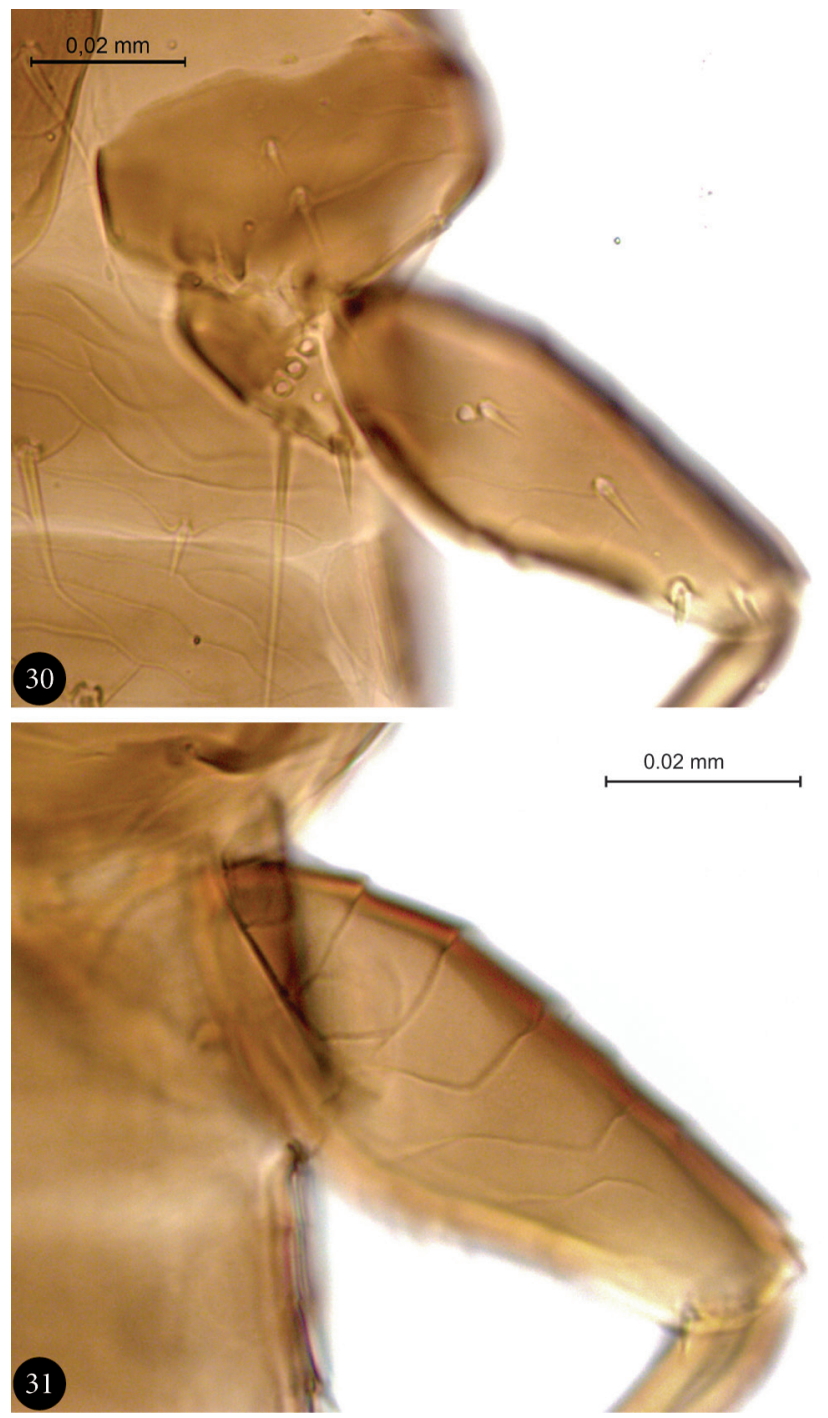

Figures 30-31. Macrosiagon octomaculata (Gerstaecker, 1855) triungulinid. Optical microscope photograph. Hind leg. (30) coxa, trochanter, and femur, ventral; (31) femur, dorsal. 

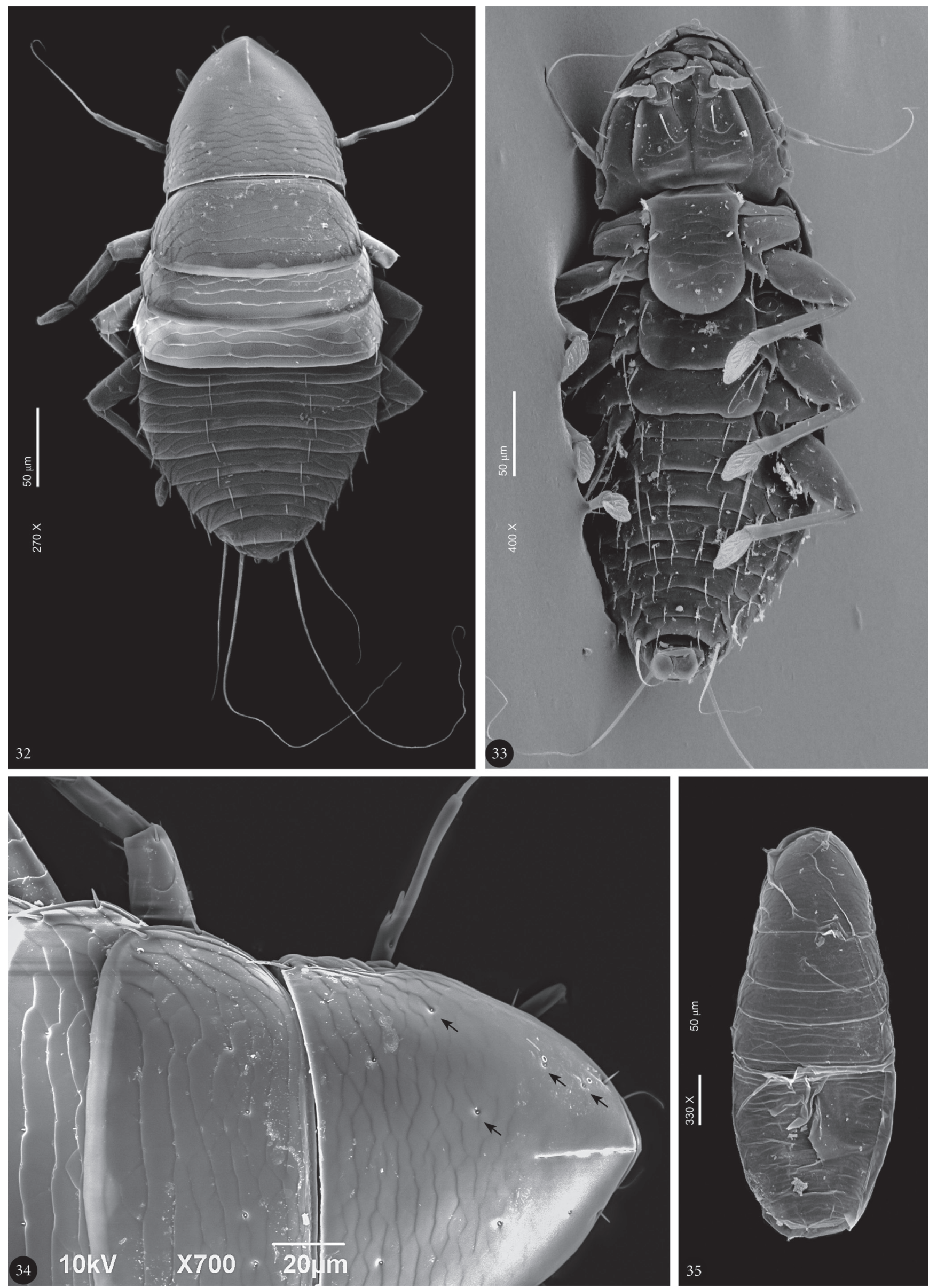

Figures 32-35. Macrosiagon octomaculata (Gerstaecker, 1855) triungulinid. SEM images. (32-33) habitus, dorsal and ventral; (34) part of head, pronotum, and mesonotum (black arrow: microsetae); (35) egg with pharate triungulinid. 

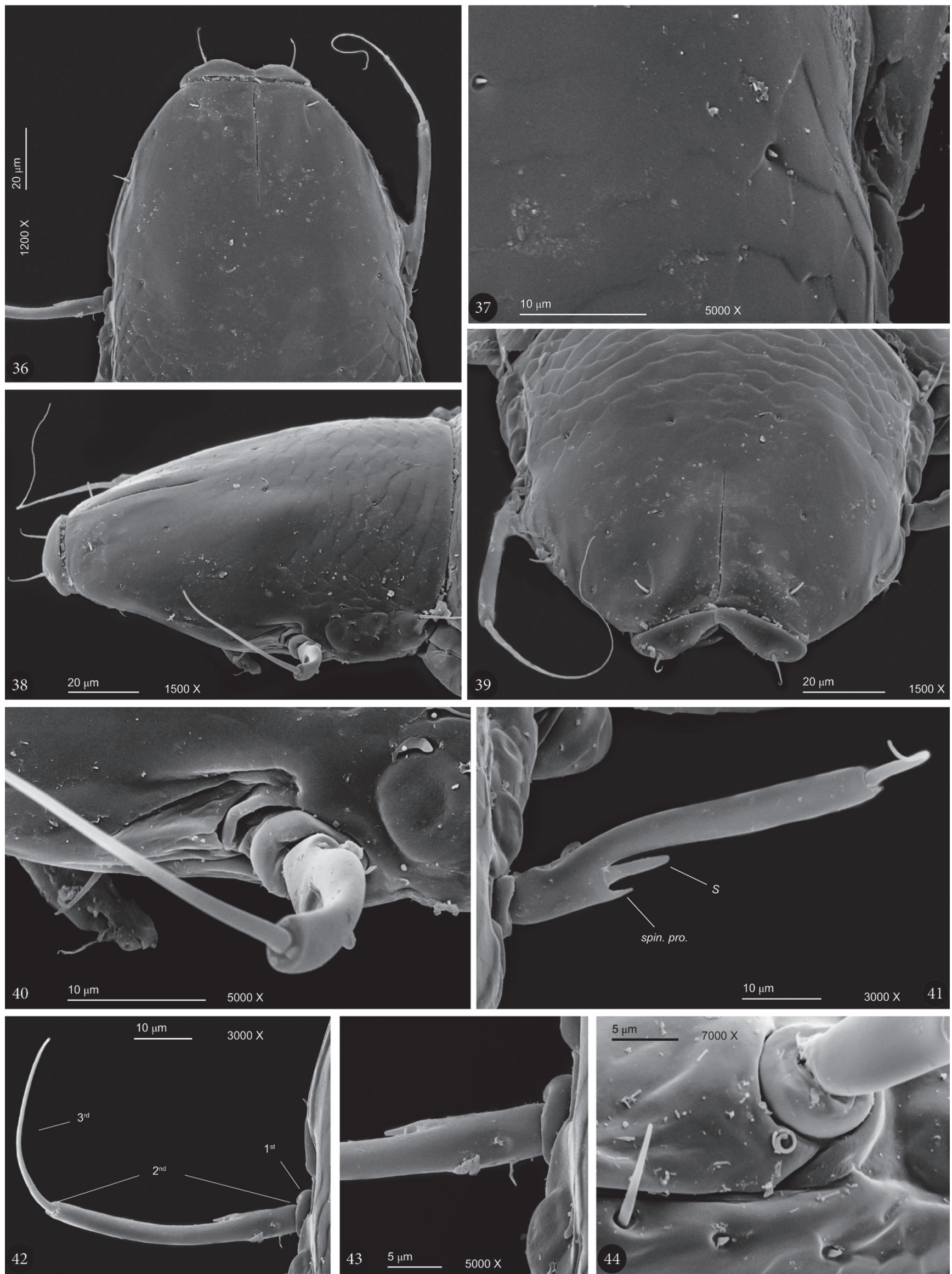

Figures 36-44. Macrosiagon octomaculata (Gerstaecker, 1855) triungulinid. SEM images. (36) head, labrum, and antennae, dorsal; (37) detail of head, with short setae, and microsculpture of integument, dorsal; (38-39) head, labrum and antennae, lateral and frontal; (40) amplification of figure 38, left antenna, lateral view of head; (41) left antenna, dorso-anterior, $S$ - sensorium; (42) left antenna, dorso-posterior; (43) detail of first antennomere and pore, dorso-posterior; (44) lateral view of antennal insertion. 

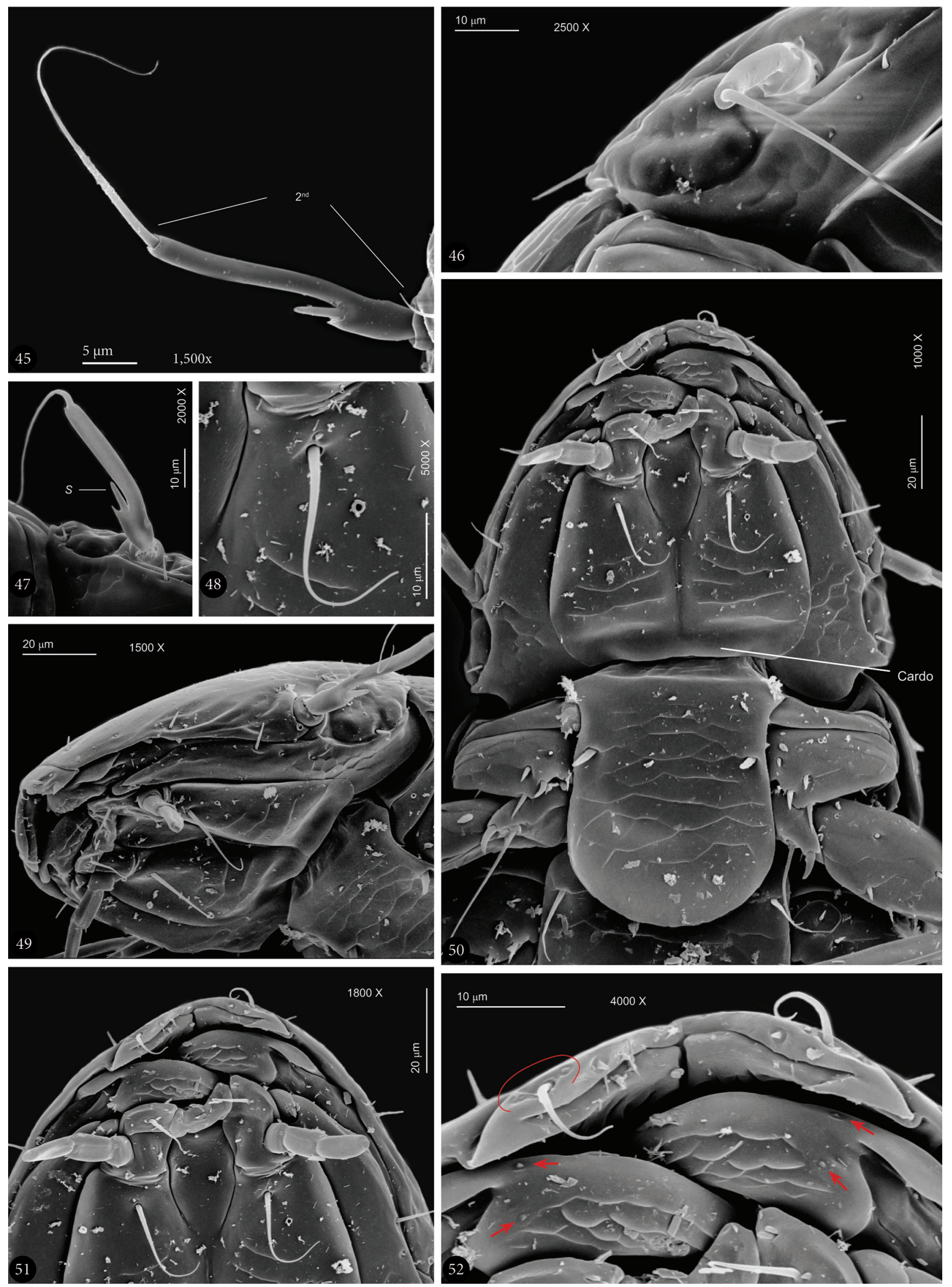

Figures 45-52. Macrosiagon octomaculata (Gerstaecker, 1855) triungulinid. SEM images. (45) right antenna, ventral; (46) right stemmata and antenna, lateral; (47) antenna, ventral, S - sensorium; (48) anterior area of right stipes; (49) head, ventro-lateral; (50) head and prothorax, ventral; (51) anterior part of head, ventral; (52) mandibles and ventro-frontal part of labrum (red circle: sensitive area of labrum; red arrow: microsetae of madibles). 

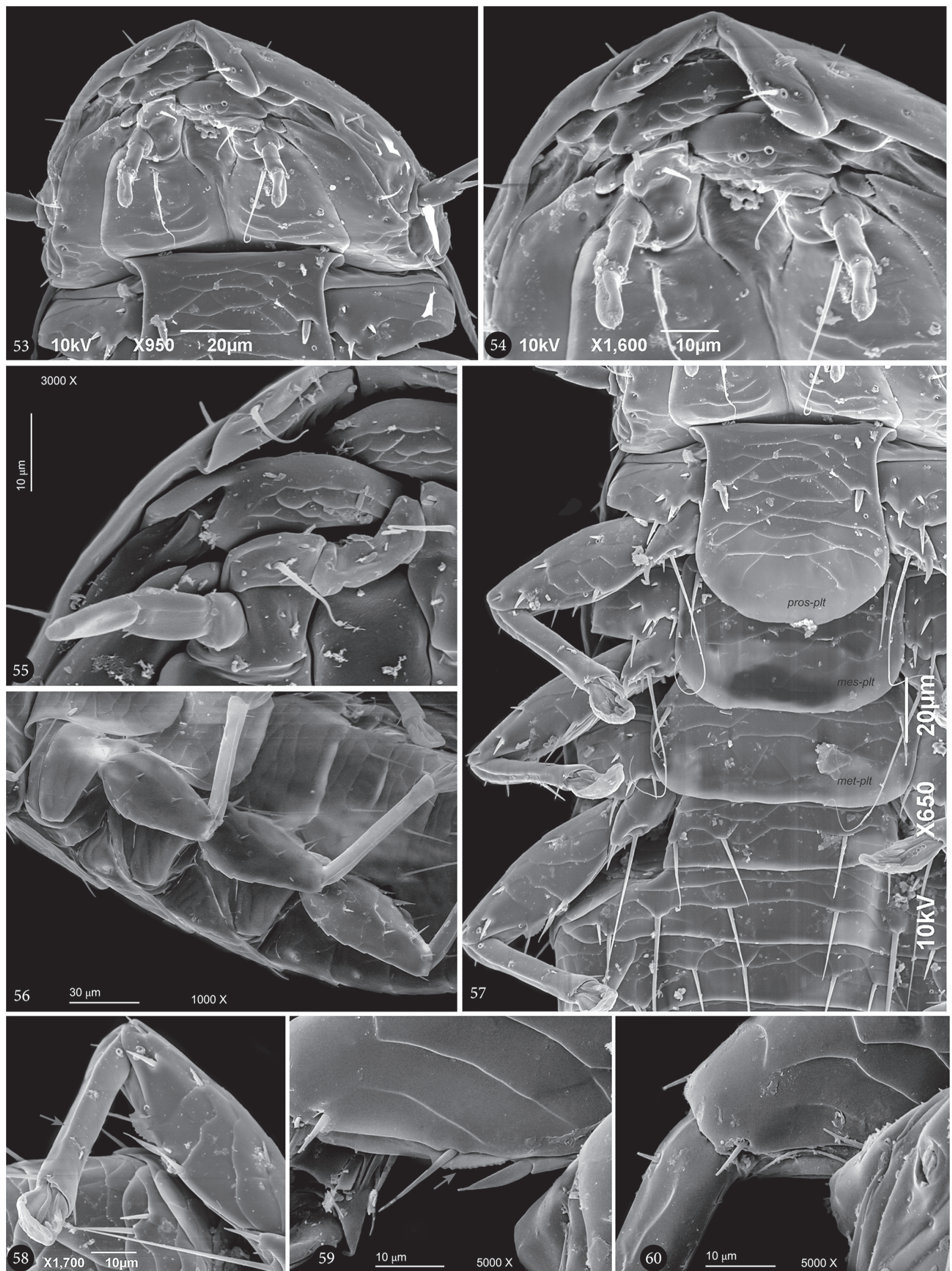

Figures 53-60. Macrosiagon octomaculata (Gerstaecker, 1855) triungulinid. SEM images. (53) head, ventral; (54) anterior part of head, ventral (red circle indicates sensitive area); (55) right side of head, ventral; (56) right legs and thoracic sclerites, ventro-lateral; (57) thorax, legs and part of abdomen, ventral, pros-plt - prosternal plate, mes-plt - mesosternal plate, met-plt - metasternal plate (red arrow: stout setae of prosternum); (58) right posterior leg, ventral (red arrow: longitudinal tibial depression, femur keel); (59) part of femur of right median leg with keel (red arrow), dorsal; (60) part of femur of right anterior leg, dorsal. 
movements of the umbel caused by the wind from those caused by being touched by hands or two flies landing on nearby umbels.

Although the feeding habits of adult Macrosiagon are mostly unknown, most are presumed to consume nectar, given their elongate proboscis-like galeae (Falin, 2002a, 2002b; Lawrence et al., 2010). However, we observed a female of M. octomaculata, in situ, feeding on the anthers and entire flowers of $P$. polyanthus, which would result in the ingestion of pollen and nectar (Fig. 78). This individual was first seen touching the capitula with its extroverted distal abdominal segments (Fig. 79), despite this behavior, no eggs were found. Eventually the female was testing by the ovipositor, the suitability of substrate to lay eggs, a common behavior in female beetles (Batelka, pers. comm.). The beetle was collected and kept alive for behavioral observation in the laboratory but, once in captivity, it barely moved and died the following day.

We found a few wasp species on $P$. polyanthus. Among the few specimens of Myzinum sp. observed, three were collected besides one Scotaena sp. and two males Scotaenini indet. One Myzinum sp. collected feeding on $P$. polyanthus flowers bores a triungulinid on the ventral side of its right hind wing (Figs. 70-72, 80-83). The triungulinid had its head pointing towards the host's body and its longitudinal axis parallel to the primary

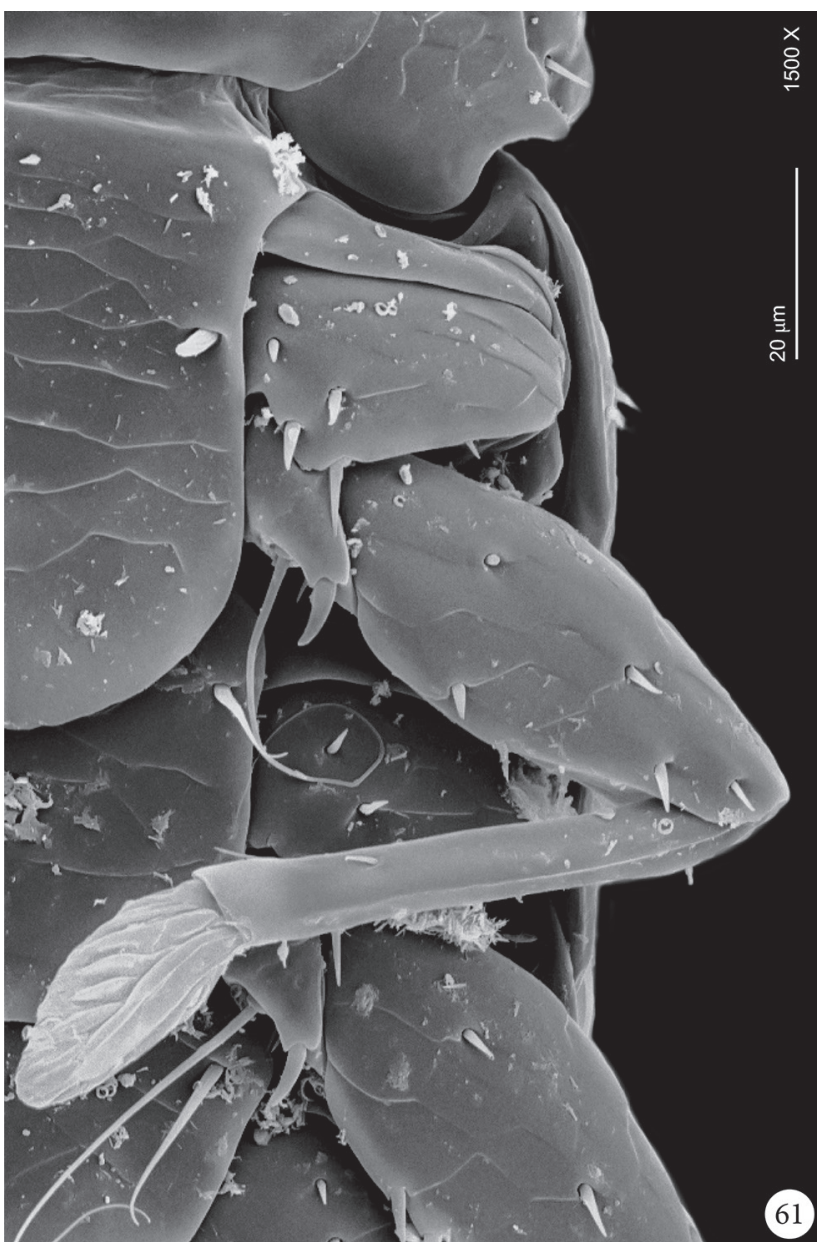

Figure 61. Macrosiagon octomaculata (Gerstaecker, 1855) triungulinid. SEM images. Left side of prosternum and foreleg showing left coxa, trochanter, femur, tibia, and pad-like pretarsus, ventral. wing veins (Fig. 81). This is identical to what was observed by Tomlin \& Miller (1989) for the triungulinids of Ripiphorus sp. attached to the wings of Halictidae bees. We postulate that Myzinum sp. is a potential triungulinid host of M. octomaculata because of its compatible size, its preference for $P$. polyanthus, and for being previously reported as host to M. sayi triungulinids (Rivnay, 1929). But it is noteworthy that this record can be accidental since usually multiple triungulinids of Ripiphorinae were reported loading on their hymenopteran host species at the same time (Batelka, 2011a).

In terms of visited and transfer plant specificity, it is feasible that in the sampled locality M. octomaculata lay eggs on plant species other than $P$. polyanthus. However, our observations on the population of $P$. polyanthus from Santa Catarina Island showed an inordinate abundance and diversity of insects associated with $P$. polyanthus. This makes it unique amongst the plants of the arid restinga areas on the island. Other plant species that are similarly
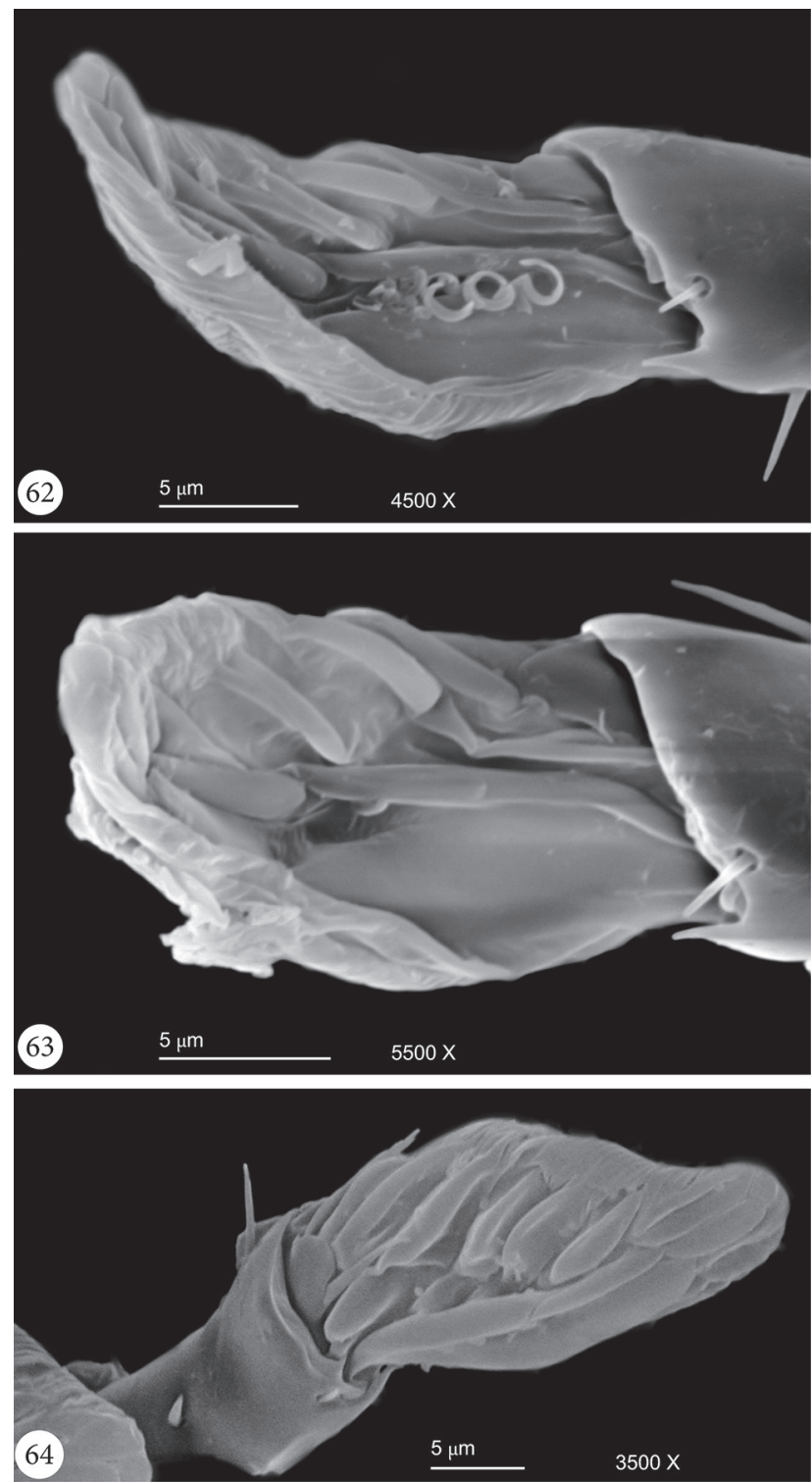

Figures 62-64. Macrosiagon octomaculata (Gerstaecker, 1855) triungulinid. SEM images. (62) median pretarsus, ventral; (63-64) posterior pretarsus, (63) ventral, (64) dorsal. 
attractive to insects, although to a lesser degree, belong to the genera Baccharis and Eupatorium (both Asteraceae). Of these, we observed a few other species of wasps, including Tiphiidae, feeding on the flowers of Baccharis sp.

\section{Remarks on larval morphology}

Until now are known first instar larvae of three subfamilies of Ripiphoridae: Ripidiinae, Ripiphorinae and Pelecotominae. The only descriptions that allow com- parisons are for Blattivorus inquirendus (Silvestri, 1906), Ripidius quadriceps Abeille de Perrin, 1872, Ripidius sp. Batelka, Perkovsky \& Prokop, 2019, and a longipedes larva gen. et sp. indet. Batelka et al., 2019b (Ripidiinae) (Silvestri, 1906; Besuchet, 1956; Batelka et al., 2019a, b); Macrosiagon ferruginea (Fabricius, 1775), Metoecus paradoxus (Linnaeus, 1761), Ripiphorus smithi Linsley \& MacSwain, 1950, and R. caboverdianus Batelka \& Straka, 2011 (Ripiphorinae) (Grandi, 1936; Chapman, 1870; Švácha, 1994; Linsley et al., 1952; Batelka \& Straka, 2011); and Pelecotoma fennica (Paykull, 1799) (Pelecotominae) (Švácha, 1994) (Table 3). Descriptions of Macrosiagon tricuspidata Lepechin, 1774 (Chobaut, 1906) and M. cucul-
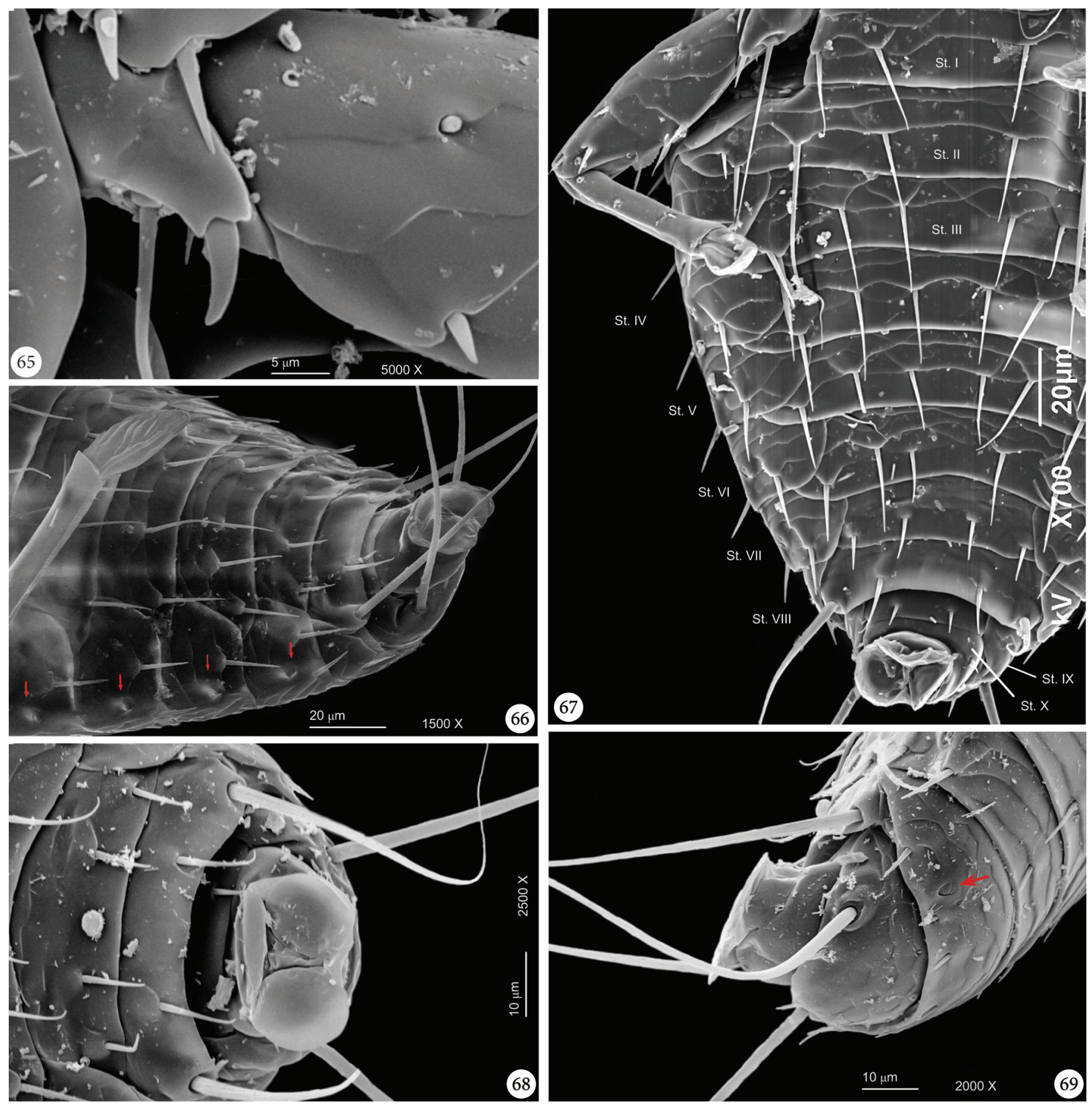

Figures 65-69. Macrosiagon octomaculata (Gerstaecker, 1855) triungulinid. SEM images. (65) foreleg, trochanter and detail of proximal area of femur, ventral; (66) abdomen, ventro-lateral, notice lateral white spots of abdominal spiracles (red arrow); (67) abdomen and right hind leg, ventral, St. I to St. IX - Sternites I to IX. (68) abdominal appendage, ventral; (69) abdominal appendage latero-posterior, note the spiracle on abdominal segment VIII (red arrow). 


\section{II \\ ‡

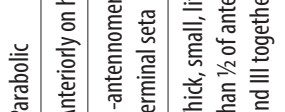

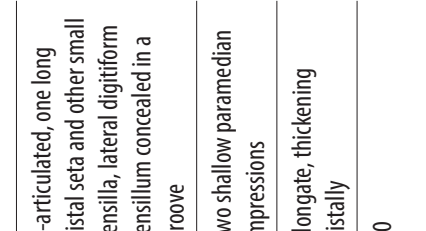

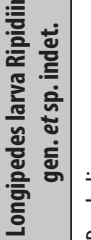

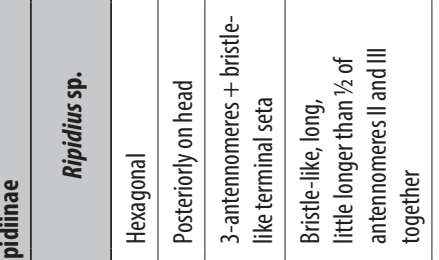
ऽ

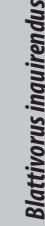

竞

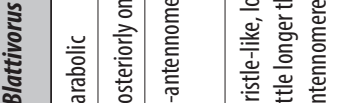

竞

홀

है

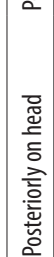
$+$

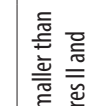

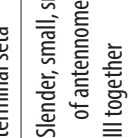

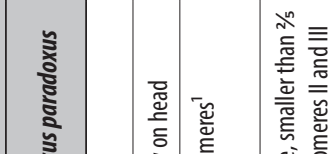

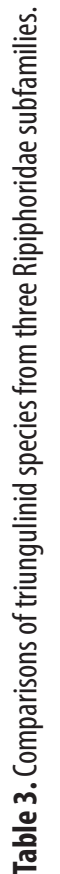

言

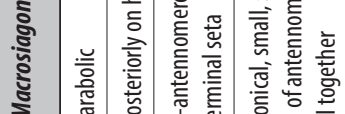

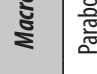

흔

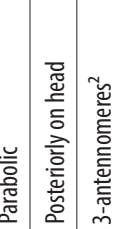

흘

就

竞芯

竞离

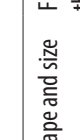

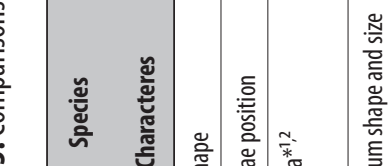
咅 I

产

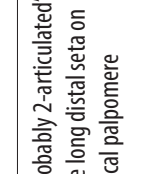

은 흥

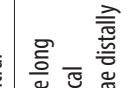

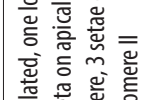

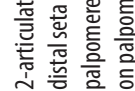

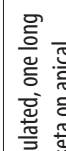

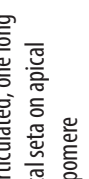

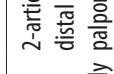

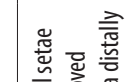

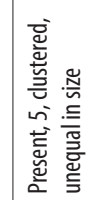

荙

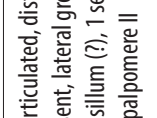

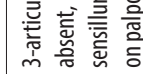

竧

要

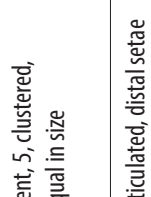

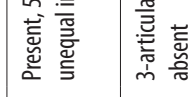

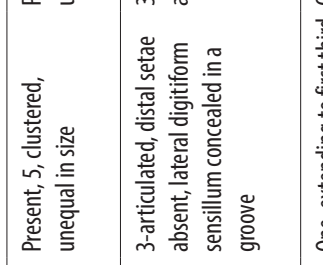

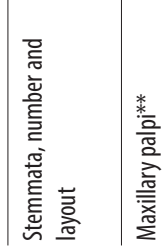

들

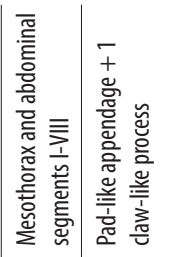

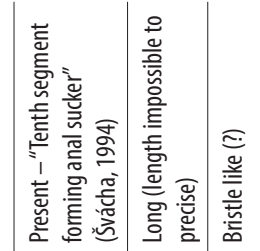

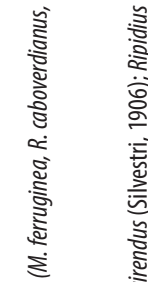

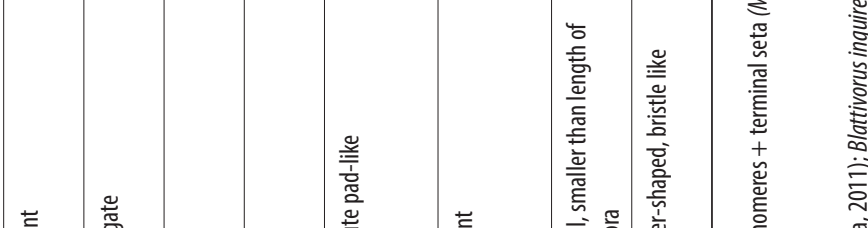

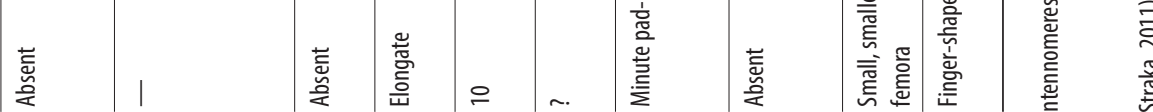


lata (Macleay, 1887) (Jarvis, 1922) are short, little detailed and poorly illustrated.

Morphological differences between the sister genera Macrosiagon and Metoecus triungulinids are tenuous. Chobaut (1891a) was the first to highlight the close resemblances between them. However, a few important taxonomical details were not described, mainly regarding the head, pretarsus and posterior abdomen, possibly owing to the methodological limitations of the time. Agreeing with Chobaut (1891a), we concluded that the triungulinid morphologies of all species in the tribe Macrosiagonini are similar and extended the similarities to all species within the genus Macrosiagon along with Me.paradoxus.

Despite the sharing of several characters between triungulinids of Macrosiagon and Metoecus, subtle differences are nevertheless discernible in the SEM images between M. octomaculata and Me. paradoxus (see Švácha, 1994 for Me. paradoxus). Compared to Macrosiagon octomaculata (in parentheses) the head of Metoecus paradoxus is dorsally irregularly striated transversally, with fine and feebly elevated lines (vs. head striated posteriorly, after ending of longitudinal mid-dorsal line); longest setae on sternum VIII, and tergum IX smaller than in Macrosiagon; abdominal segment $\mathrm{X}$ rectangular, longer than wide (vs. subquadrate, slightly wider than long); keels at the ventral margin of median and hind legs absent (vs. present). Nevertheless, as molecular evidence recovers Metoecus internal to Macrosiagon (Batelka et al., 2016), these differences may only concern to species boundaries of the same genus.

The abdominal appendage is a membranous region which can be partially invaginated (Grandi, 1936; Tomlin \& Miller, 1989) and has not been described for Macrosiagon (Grandi, 1936), Ripiphorus (Linsley et al., 1952; Batelka \& Straka, 2011), Metoecus triungulinids (Chapman, 1870; Švácha, 1994), and Pelecotoma fennica (Švácha, 1994). The term pygopod was used to designate the membranous and retractable terminal region of the abdomen (Grandi, 1936), which Chobaut (1891a, b) referred to as a modification related to host adhesion and for which Tomlin \& Miller (1989) confirmed the capacity for adhesion to smooth substrates. Tomlin \& Miller (1989) defined the pretarsus as being characterized by leafshaped pulvilli or an inflatable lobe and Pohl \& Beutel (2004) termed it the pretarsal bladder, which they defined as a highly developed membranous lobe or pad. However, the most recent study on extant Ripidiinae larvae (Batelka et al., 2019a) applied the term abdominal appendage, which we follow. Batelka (2011a) highlighted the need for a more detailed description of this phoretic character. Based on the illustrations presented in the above-mentioned literature and this study for all Ripiphorinae genera we noticed that the abdominal appendages of Macrosiagon are bilobate and one-segmented, Metoecus seem to be bilobate and one-segmented, and Ripiphorus appear to be undivided and one-segmented. In Ripidiinae the abdominal appendage shape is more variable between genera and in some cases absent. In Blattivorus inquirendus is tubular and one-segmented (see fig. 10 in Silvestri, 1906), in the two Ripidius species are three-segmented and tubular, and absent in the longipedes larva of Ripidiinae gen. et sp. indet. For Pelecotoma the images do not allow comparison. This indicates the potential use of the abdominal appendage (if present) as a taxonomic character to distinguish Ripidiinae from Ripiphorinae.

In the literature, the number of abdominal segments of ripiphorid triungulinids was assumed to be nine (Silvestri, 1906; Böving \& Craighead, 1931; Besuchet, 1956; Bologna et al., 2010), nine or 10 (Chapman, 1870) and 10 (Grandi, 1936; Costa et al., 1988; Linsley et al., 1952; Selander, 1991a, b; Švácha, 1994; Lawrence et al., 2010; Batelka et al., 2019a, b; this study). This variation is likely related to the retractable nature of the abdominal appendage and the methods used to study the larvae. Based on our observations, we could correlate methods of specimen preparation with the pleura distension or contraction. Depending on the preparation performed (ethanol, $\mathrm{KOH}+$ acetic acid or lactic acid) the form of the abdominal segments varies, especially the distal segments, explaining this discrepancy between the numbers of visible segments.

Linsley et al. (1952) was the first to point out the variations between the triungulinids of Macrosiagon and Ripiphorus. Compared to Ripiphorus (in parentheses), the triungulinids of Macrosiagon are more elliptical (vs. subcylindrical), bear a longitudinal mid-dorsal line on

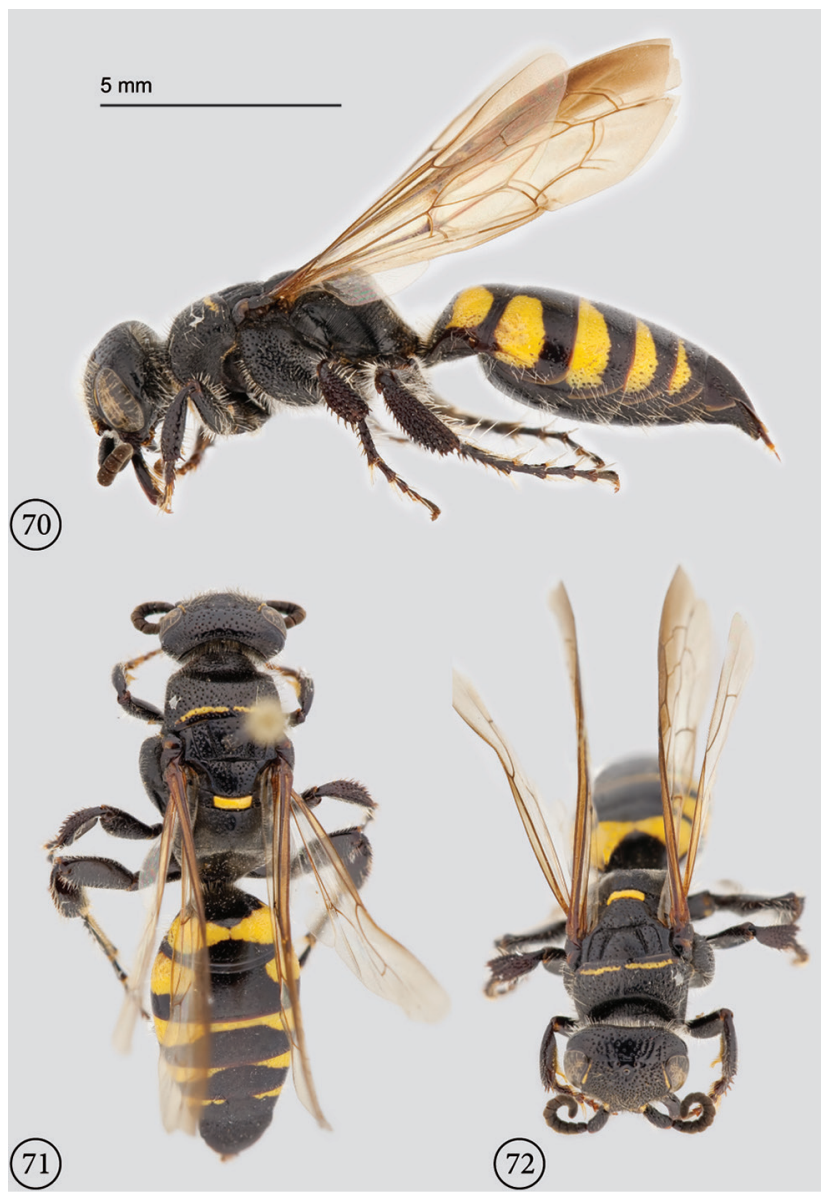

Figures 70-72. Myzinum sp. (Thynnidae) habitus. (70) lateral; (71) dorsal; (72) fronto-dorsal. Scale bar refers only to Figure 70. 
the head (vs. absent); possess eight pairs of spiracles on abdominal pleura and three pairs on the thorax (vs. spiracles on mesothorax and abdominal segment VIII); one pair of long setae on sternum VIII and tergum IX, setae are longer than segments $\mathrm{VI}$ to $\mathrm{X}$ (Vs. short setae, setae shorter or about as long as segment $\mathrm{X}$ ) (apicolateral setae in Batelka \& Straka, 2011) and abdominal segment $X$ is subquadrate with a bilobate appendage (conical, not accessed). Also, following our interpretation of the antennomeres (see below), the antennomere II of Macrosiagon triungulinids are one third longer than in Ripiphorus; and the cardo and stipes are not fused (vs. fused).

Distinctions between Macrosiagon and the Ripidiinae genera Blattivorus and Ripidius are remarkable. Among the most noticeable are (Macrosiagon in parenthesis): head length almost equal or shorter than head width (almost equal or greater); sternal thoracic plates absent, or apparently present but small in Blattivorus (present and well developed going beyond coxa); tibia strongly thinned compared to femur, longer than femur and bearing several setae, posterior tibia longer than others in Blattivorus (tibia of subequal thickness compared to femur, almost as long as femur and bearing a couple of setae, equal in length); the chaetotaxy of Ripidiinae is composed of several stout setae dorsally on head, dor- sally and ventrally on thoracic segments and on few abdominal sternites, besides filiform setae (only one pair of stout setae on prosternal plate); one long seta present distally on apical maxillary palpomere, as long as or longer than all palpomeres together (seta absent). However, still more different from Macrosiagon is Pelecotoma. The latter is supposed not to bear phoretic habit and thus, does not bear the common triungulinid forms of first instar Ripiphoridae (Švácha, 1994). The body form of Pelecotoma first instar larva is slender and elongate, some parts are barely sclerotized, antennae reduced comparing to head length, only two stemmata are present and pretarsus bears a sickle-like claw. Further comparisons are present in Table 3.

Batelka et al. (2019a) discussed on the discrepancy between the interpretations of the number of antennomeres in Ripiphoridae larvae by different authors - Silvestri (1906), Grandi (1936), Besuchet (1956) and Švácha (1994). Batelka concluded that it is impossible to decide whether the arrangement of larval antennomeres of Ripidius sp. is the same from other described Ripidiinae - Blattivorus inquirendus (Silvestri, 1906) and Ripidius quadriceps (Besuchet, 1956) - or if it has been overlooked in these Ripidiinae, or yet, if it is an artefact of fossilization. Moreover, Batelka pointed out that his
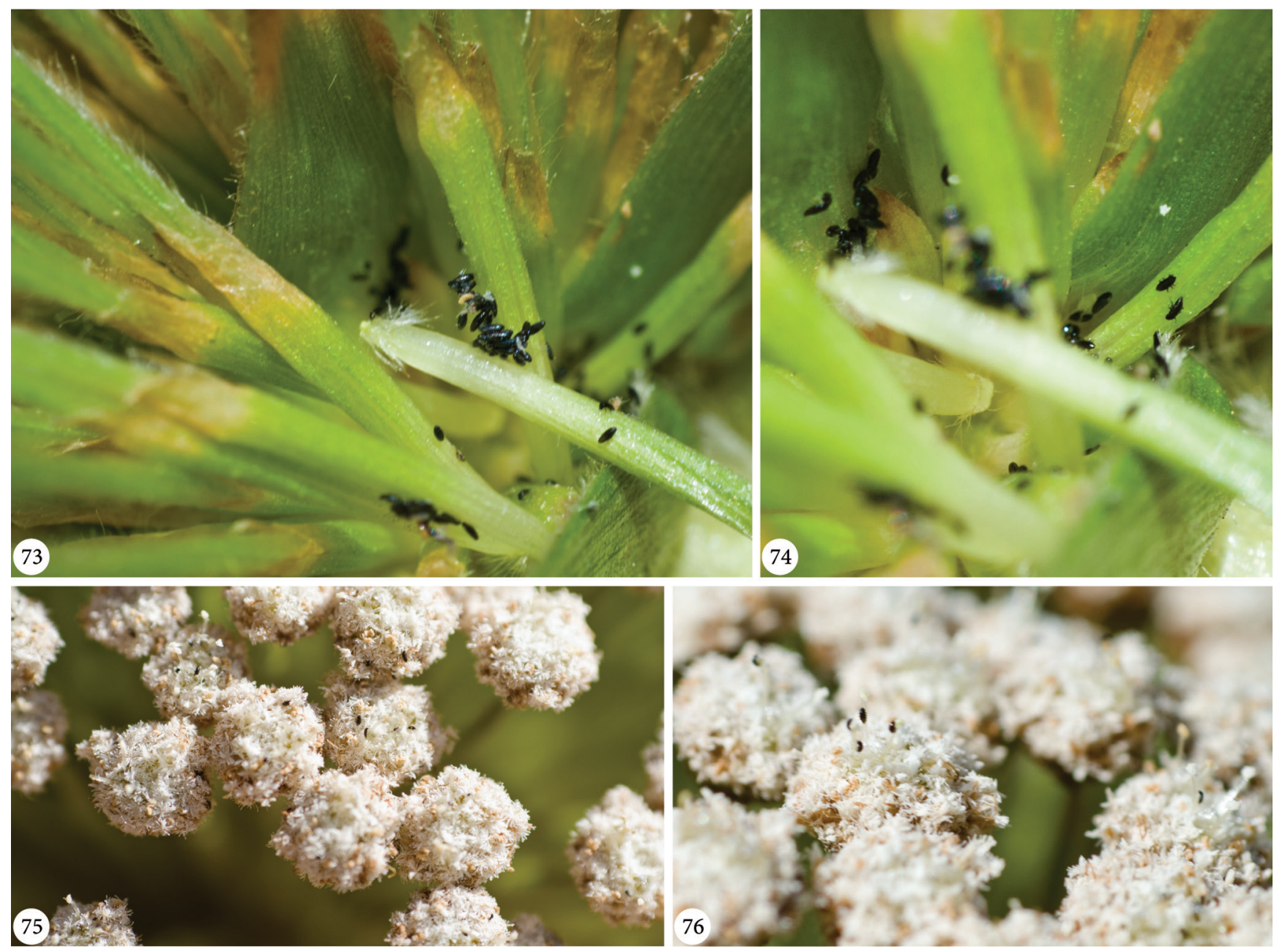

Figures 73-76. Macrosiagon octomaculata (Gerstaecker, 1855) and Paepalanthus polyanthus Bong (Sano). (73-74) eggs with pharate triungulinids and triungulinids recently hatched on the base of scapes; (75-76) triungulinids actively occupying the upper part of the plant, crawling on the flowers and at the top of anthers. 

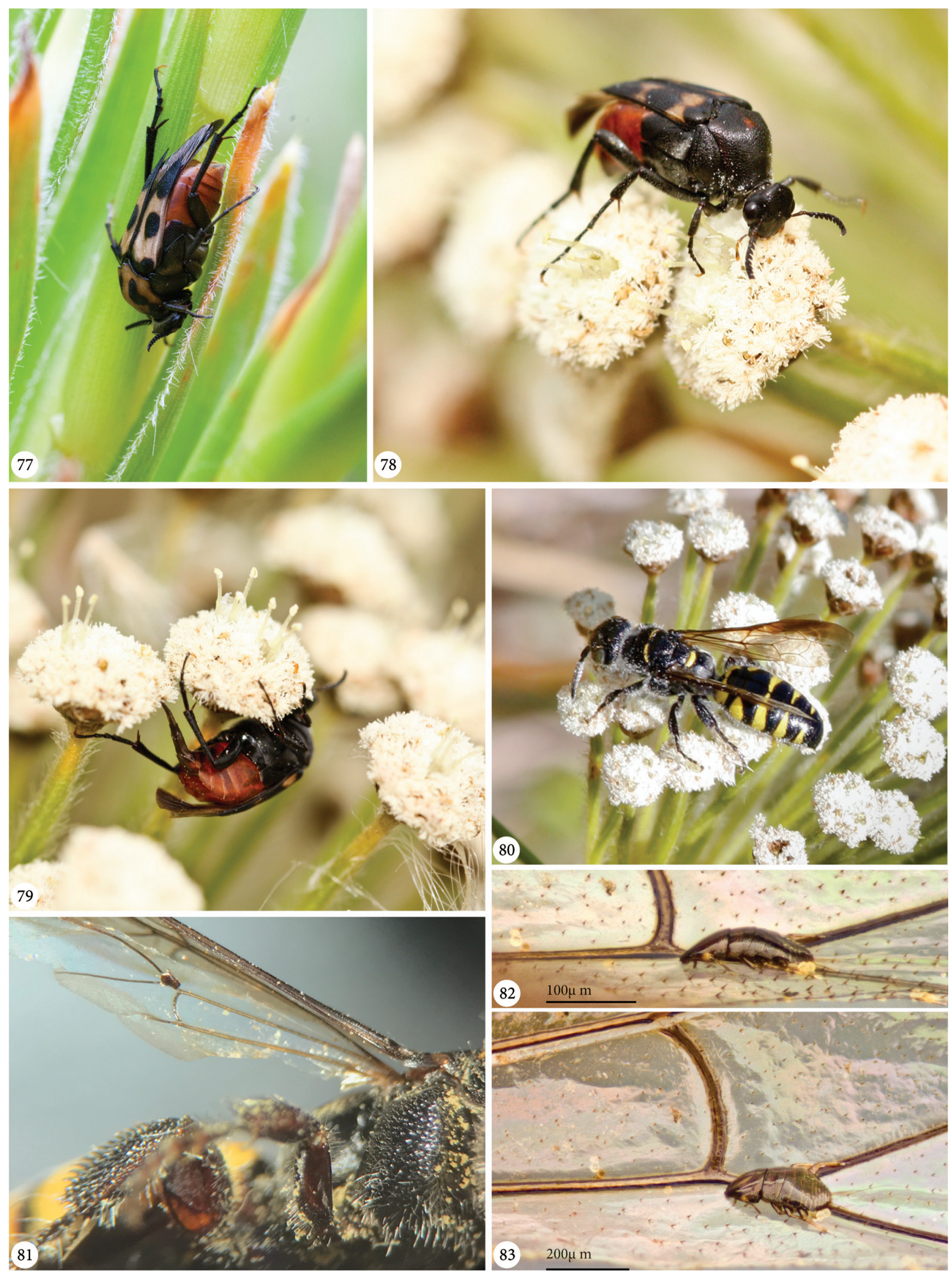

Figures 77-83. Macrosiagon octomaculata (Gerstaecker, 1855) and Myzinum sp. (Thynnidae) in natural habit. (77) light brown phenotype female resting on Paepalanthus polyanthus leaves; (78) female in the field feeding on capitula of $P$. polyanthus; (79) female with ovipositor everted touching flowers of capitula; (80) Myzinum sp. feeding on the flowers of umbel; (81) Myzinum sp. with one triungulinid anchored on its wing, note that larva is facing towards the wasp body and parallel to the wing vein; (82-83) triungulinid attached to the wasp wing, (82) lateral, (83) dorso-lateral. 
interpretation (3 antennomeres plus 1 terminal bristle-like seta) is corroborated by Švácha (1994) (studying Pelecotoma) and Grandi (1936) (studying Macrosiagon). Batelka et al. (2019a) interpretation also agrees with those of Chobaut (1906), Linsley et al. (1952) and Batelka \& Straka (2011). However, based on our SEM images and on observations under optic microscopy after lactic and acetic acid treatments of the triungulinids, our interpretation agrees with the interpretation of Silvestri (1906) and Besuchet (1956). This last interpretation also understands an antennae with 3 antennomeres antennae, but, in another way, considering the terminal bristle like setae as the third whip-like antennomere, and what was previously interpreted as antennomeres II and III is here, considered the antennomere II. These previous interpretations seem to be the result of the constriction on the basal third of the antennomere II that appears as a division between segments under optic microscopy, but is evident in SEM images. Unfortunately, the antennal descriptions of Ripiphorus do not provide SEM images and relevant information on these characters to determine whether they too share the same antennal structure and thus, further investigation is required to confirm this.

Likewise, light microscopy only enables the observation of abdominal spiracles on segment eight, which are located dorsally and are the easiest to observe. However, SEM images provided the first observations of spiracles on all thoracic segments as well as on abdominal segments I to VII. Therefore, the usage of SEM images is an essential tool for the study and characterization of triungulinid morphology.

The phoretic habits of $M$. octomaculata triungulinids involve their attachment to flying hosts for transport to the host species' nest. Tomlin \& Miller (1989) examined the strength of forces involved in their attachment to the host's wing and found at least three forces involved: centripetal acceleration ("the tendency to 'throw' the attached ripiphorid towards wing apex because of rotation around wing hinge"), tangential acceleration ("approximately perpendicular to the wing"), and aerodynamic drag. As a result, structures are present that ensure that these forces are overcome and the triungulinid reaches the host's nest. Most relevant are the sucker-like pretarsi, which they share with Strepsiptera triungulinids; and the soft, sucker-like and moveable abdominal appendage (Selander, 1991a; Pohl \& Beutel, 2004, 2008; Tomlin \& Miller, 1989). However, these structures alone may not be enough to prevent detachment from the Hymenoptera wing during flight.

Other characters that are likely associated with the phoresy include:

1) The antenna. The prolongation of the antennomere after the sensorium is uncommon in Coleoptera larvae (Costa et al., 1988), however, there is relatively scarce information regarding first instar morphology. We suggest that the prolongation of the antennomere II to beyond sensorium in association with the spine adjacent the sensorium and the whip-like third antennomere are morphological features relat- ed to the phoretic habits of first instar Coleoptera. It is presumably involved in anchoring the larvae to the host during its phoretic phase (Figs. 82-83). In families in which the first instar larvae show similar phoretic behavior, namely the Ripiphoridae and Meloidae, the antennae share these similar morphological characters. On the other hand, triungulinids of Strepsiptera lack developed antennae. However, Strepsiptera first instar larvae display a wide range of mechanisms to attach themselves to their hosts, besides having more specialized morphological structures covering the entire body that enhance their anchorage to the host. In the families Xenidae and Stylopidae, which display phoresy, like Ripiphoridae, morphological structure associated to phoretic adhesion are remarkable, as modified labium structures and the well-developed rows of robust spine-like prolongations on body segments (Batelka, pers. comm.; Linsley et al., 1952; Selander, 1991a, b; Švácha, 1994; Pohl, 2002; Pohl \& Beutel, 2004; Batelka \& Straka, 2011).

2) Ventral setae. The ventral setae are all posteriorly orientated. This may assist in attachment to the host and provide an answer to the question of "Why do triungulins lie parallel to the main vein and always face their heads towards the body of the halictid host" (Tomlin \& Miller, 1989). In this position the longitudinal axis of a triungulinid is parallel to the direction of centripetal acceleration, and thus, the ventral setae oppose this force, keeping it attached.

3) Attachment to a vein. As for all the triungulinids found on host wings by Tomlin \& Miller, (1989), those that we found were attached to a wing vein. Veins are sclerotized and therefore less susceptible to surface instability than the membranous area. Furthermore, the stability of the triungulinid body is improved by the four long setae on sternum VIII and tergum IX, which may act similarly to the tail of a kite, to enhance balance and reduce drag.

4) The design of the integument surface is important to reduce friction (Luo et al., 2015). For triungulinids, the integument surface resembles other surfaces that are known to increase slip velocity, decreasing drag at the high air speeds experienced by the larvae (Chear \& Dol, 2015; Razzak, 2018). Nevertheless, the aerodynamic qualities of the triungulinid integument surface requires testing using experimental models.

\section{ACKNOWLEDGMENTS}

We are very grateful to Sônia Casari and Gabriel Biffi for the invitation to submit a manuscript in this special issue of PAZ celebrating the $80^{\text {th }}$ birthday of Prof. Cleide Costa; and to Jan Batelka and one anonymous reviewer for providing comments and corrections on the manuscript. We also thank Elise L. Galitizk (Universidade Federal de Santa Catarina - UFSC) for showing us the first Macrosiagon octomaculata from $P$. polyanthus; Carlos Eduardo V.B.D. de Siqueira (Centro de Informática e Automação do Estado de Santa Catarina) for helping 
in field work; Carlos José de C. Pinto, Benedito C. Lopes and Josefina Steiner for their support at UFSC; Zachary $\mathrm{H}$. Falin (University of Kansas, Biodiversity Institute, USA) and Lynn S. Kimsey (University of California - UC Davis, USA) for verifying the Ripiphoridae and wasp identification respectively; Jan Batelka (Charles University, Czech Republic) for supplying us with references; Michel P. Valim (MZSP) for access to the optical microscope linked to digital camera and for suggestions on triungulinid treatment; André Vieira da Rosa (in memoriam) for aerial photography of the collection field; Carlos R.F. Brandão and Marcelo Duarte for access to MZSP facilities; Letícia de Almeida Gonçalves for access to UFG facilities; and Fundação de Amparo à Pesquisa do Estado de São Paulo - FAPESP and Conselho Nacional de Desenvolvimento Científico e Tecnológico - CNPq for financial support to F.F. Albertoni (FAPESP 2012/02441-1) and M.A. Ulysséa (FAPESP 2012/21309-7, 2015/06485-1, 2018/11453-0; PROTAX/FAPESP 2016/50378-8). The scientific contributions proposed here were only possible by funding and support of various institutions, which have been severely threatened by the Brazilian government.

\section{REFERENCES}

Andrade, M.J.G. de; Giulietti, A.M.; Rapini, A.; Queiroz, L.P. de; Conceição, A. de S.; Almeida, P.R.M. de \& Berg, C. van den. 2010. A comprehensive phylogenetic analysis of Eriocaulaceae: Evidence from nuclear (ITS) and plastid (psbA-trnH and trnL-F) DNA sequences. Taxon, 59(2): 379-388.

Barber, H.S. 1915. Macrosiagon flavipennis in cocoon of Bembex spinolae (Coleoptera: Rhipiphoridae). Proceedings of the Entomological Society of Washington, 17: 187-188.

Barclay, M.V.L. 2015. Ivierhipidius, an enigmatic new Neotropical genus of Ripiphoridae (Coleoptera: Tenebrionoidea) with four new species. Acta Entomologica Musei Nationalis Pragae, 55(2): 691-701.

Batelka, J. 2004. Contribution on the synonymy of Palaearctic and Oriental species of Macrosiagon (Coleoptera: Ripiphoridae). Part Il. Acta Societatis Zoologicae Bohemicae, 68: 9-13.

Batelka, J. 2007. Taxonomy and distribution of Palaearctic and Oriental species of the genus Macrosiagon (Coleoptera: Ripiphoridae). Part III. Bulletin de la Société Entomologique de France, 112: 239-248.

Batelka, J. 2010. A review of Ripiphoridae in the Arabian Peninsula (Coleoptera: Tenebrionoidea). Acta Entomologica Musei Nationalis Pragae, 50(1): 157-166.

Batelka, J. 2011a. Primary larvae of some Ripiphorinae: their phoresy and dispersal (Coleoptera: Ripiphoridae). Acta Entomologica Musei Nationalis Pragae, 51(2): 731-756.

Batelka, J. 2011b. Contribution to the synonymies, distributions, and bionomics of the Old World species of Macrosiagon (Coleoptera: Ripiphoridae). Acta Entomologica Musei Nationalis Pragae, 51(2): 587-626.

Batelka, J. 2013. A review of the genus Macrosiagon in Laos (Coleoptera: Ripiphoridae). Entomologica Basiliensia et Collections Frey, 34: 319-325.

Batelka, J. \& Chaboo, C.S. 2015. Beetles (Coleoptera) of Peru: A Survey of the Families. Ripiphoridae Gemminger and Harold, 1870. Journal of the Kansas Entomological Society, 88(3): 399-403. DOI

Batelka, J. \& Hoehn, P. 2007. Report on the host-associations of the genus Macrosiagon (Coleoptera: Ripiphoridae) in Sulawesi (Indonesia). Acta Entomologica Musei Nationalis Pragae, 47: 143-152.
Batelka, J. \& Straka, J. 2011. Ripiphorus caboverdianus sp. nov. - the first ripiphorid record from the Macaronesian volcanic islands (Coleoptera: Ripiphoridae: Ripiphorinae). Zootaxa, 2792: 51-62.

Batelka, J.; Kundrata, R. \& Bocak, L. 2016. Position and relationships of Ripiphoridae (Coleoptera: Tenebrionoidea) inferred from ribosomal and mitochondrial molecular markers. Annales Zoologici, 66(1): 113-123. D0I

Batelka, J.; Perkovsky, E.E. \& Prokop, J. 2019a. Diversity of Eocene Ripiphoridae with descriptions of the first species of Pelecotominae and larva of Ripidiinae (Coleoptera). Zoological Journal of the Linnean Society, 188(2): 412-433. DOI

Batelka, J.; Prokop, J.; Pohl, H.; Bai, M.; Zhang, W. \& Beutel, R.G. 2019b. Highly specialized Cretaceous beetle parasitoids (Ripiphoridae) identified with optimized visualization of microstructures. Systematic Entomology, 44: 396-407. DOI

Bequaert, J.C. 1918. A revision of the Vespidae of the Belgian Congo based on the collection of the American Museum Congo Expedition, with a list of Ethiopian diplopterous wasps. Bulletin of the American Museum of Natural History, 39: 1-384.

Besuchet, C. 1956. Biologie, morphologie et systematique des Rhipidius. Mitteilungen der Schweizerischen Entomologischen Gesellschaft, 29: 73-144.

Bologna, M.A.; Turco, F. \& Pinto, J.D. 2010. 11.19 Meloidae Gyllenhal 1810. In: Leschen, R.A.B.; Beutel, R.G. \& Lawrence, J.F. (Eds.). Coleoptera, Beetles. Vol. 2: Morphology and systematics (Elateroidea, Bostrichiformia, Cucujiformia partim). Berlin, Walter de Gruyter. p. 681-693. (Handbook of Zoology, Arthropoda: Insecta)

Böving, A.G. \& Craighead, F.C. 1931. An illustrated synopsis of the principal larval forms of the order Coleoptera. Entomologica Americana, 11: 1-351.

Callan, E. McC. 1981: Further records of Macrosiagon (Coleoptera: Rhipiphoridae) reared from eumenid and sphecid wasps in Australia. Australian Entomological Magazine, 7: 81-83.

Campbell, J.M. 1991. Family Rhipiphoridae: wedge-shaped beetles. In: Bousquet, Y. (Ed.). Checklist of Beetles of Canada and Alaska. Ottawa, Agriculture Canada, Research Branch. p. 250-251. (Publication 1861/E).

Castellani, T.T. \& d'Eça-Neves, F.F. 2000. Population ecology of Paepalanthus polyanthus: Predispersal hazards and seed production. Acta Botânica Brasileira, 14(3): 317-326.

Castellani, T.T.; Scherer, K.Z. \& Paula, G.S. 2001. Population ecology of Paepalanthus polyanthus (Bong.) Kunth: demography and life history of a sand dune monocarpic plant. Revista Brasileira de Botânica, 24(2): 123-134.

Castellani, T.T.; Vieira, S. \& Scherer, K.Z. 1996. Contribuição ao conhecimento da distribuição espacial de Paepalanthus polyanthus (Bong.) Kunth (Eriocaulaceae) em áreas de baixada úmida de dunas. Acta Botânica Brasilica, 10: 25-36.

Chapman, T.A. 1870. Some facts towards a life-history of Rhipiphorus paradoxus. Annals and Magazine of Natural History, Serie 4, 6: 314-326.

Chear, C.K. \& Dol, S.S. 2015. Vehicle Aerodynamics: Drag Reduction by Surface Dimples. International Journal of Mechanical, Aerospace, Industrial, Mechatronic and Manufacturing Engineering, 9(1): 202-205.

Chobaut, A. 1891a. Mours et métamorphoses de Emenadia flabellata $\mathrm{F}$. Insecte coléoptères de la famille des Rhipiphorides (1). Annales de la Société Entomologique de France, 60: 447-456.

Chobaut, A. 1891b. Mœurs et métamorphoses de L'Emenadia flabellata. Annales des Sciences Naturelles, Zoologia et Paléontologia, 12: 97-112.

Chobaut, A. 1895. Étude sur les Macrosiagon Hentz (Emenadia Lap.-Cast.) de la région méditerranéenne. I. Moeurs et métamorphoses des Macrosiagon. L'Abeille Journal d'Entomologie, 28: 181-183.

Chobaut, A. 1906. Le triongulinide de Macrosiagon tricuspidata Lepech. [Col.]. Bulletin de la Société Entomologique de France, (1906): 270-272. 
Cillo, D.; Mura, R. \& Bazzato, E. 2019. On the presence of Macrosiagon ferruginea (Fabricius, 1775) in northern Tunisia (Coleoptera, Ripiphoridae, Ripiphorinae, Macrosiagonini). Entomological News, 128(4):351-355. D0I

Clausen, C.P. 1940. Entomophagous Insects. New York, McGraw-Hill. x +688p.

Clausen, C.P. 1976. Phoresy among entomophagous insects. Annual Review of Entomology, 21: 343-367.

Coll, F.E. 1942. Los representantes catalanes de la família "Rhipiphoridae" (Col.). Anales de la Escuela de Peritos Agrícolas y Superior de Agricultura y de los Servicios Técnicos de Agricultura, 2(4):335-346.

Costa, C.; Vanin, S.A. \& Casari-Chen, S.A. 1988. Larvas de Coleoptera do Brasil. São Paulo, Museu de Zoologia, Universidade de São Paulo. 282p.

Davis, J.J. 1919. Contributions to knowledge of the natural enemies of Phyllophaga. Bulletin of the Illinois State Natural History Survey Bulletin, 13: $53-138+15 \mathrm{pl}$.

Dodd, A.P. 1917. The Cane Grubs of Australia. Part II. Being a continuation of the results of investigations as commenced in Bulletin No. 2. Bulletin. Division of Entomology, Bureau of Sugar Experiment Stations, Queensland, 6:1-30.

Elliott, M.G. 2011. Annotated catalogue of the Australian Scoliidae (Hymenoptera). Technical Reports of the Australian Museum, 22: 1-17. $\underline{\mathrm{DOl}}$

Evans, H.E.; Matthews, R.W. \& Hoo, A. 1966. Notes on the nests and prey of six species of Pison in Australia (Hymenoptera: Sphecidae). Psyche, 87: $221-230$.

Falin, Z.H. 2002a. Ripiphoridae Gemminger and Harold 1870 (1853). In: Arnett, R.H.; Thomas, M.C.; Skelley, P.E. \& Frank, J.H. (Eds.). American Beetles. Volume 2, Polyphaga: Scarabaeoidea through Curculionoidea. Florida, CRC Press. p. 431-444.

Falin, Z.H. 2002b. Notes on the South American ripiphorid Macrosiagon vittula (Coleoptera: Ripiphoridae). Entomological News, 113(3): 192-196.

Falin, Z.H. 2003. Phylogenetic analysis and revision of the genera and subfamilies of Ripiphoridae (Coleoptera). PhD Thesis, University of Kansas. 560p.

Falin, Z.H. 2004. Revision of three new world Macrosiagon Hentz species (Coleoptera: Ripiphoridae: Ripiphorinae) with a discussion of phylogenetic relationships within the Macrosiagonini. The Coleopterists Bulletin, 58: 1-19.

Falin, Z.H. \& Engel, M.S. 2014. A new genus and two new extant species closely allied with the fossil genus Pauroripidius (Coleoptera: Rhipiphoridae). Journal of the Kansas Entomological Society, 87(4): 333-344.

Falin, Z.H.; Arneson, L.C. \& Wcislo, W.T. 2001. Night-flying sweat bees Megalopta genalis and Me. Acuadoria (Hymenoptera: Halictidae) as host of the Parasitoid beetle Macrosiagon gracilis (Coleoptera: Rhipiphoridae). Journal of the Kansas Entomological Society, 73(3): 183-185.

Farines, M. 1826. Observations sur la larve du Ripiphorus bimaculatus. Annales des Sciences Naturelles, Paris, 8: 244.

Fernández, F.F. \& Sharkey, M.J. (Eds). 2006. Introducción a los Hymenoptera de la región neotropical. Bogotá D.C., Sociedad Colombiana de Entomología y Universidad Nacional de Colombia. xxx + 894p.

Genaro, J.A. 1996. Nest parasites (Coleoptera, Diptera, Hymenoptera) of some wasps and bees (Vespidae, Sphecidae, Colletidae, Megachilidae, Anthophoridae) in Cuba. Caribbean Journal of Science, 32(2): 239-240.

Gerstaecker, A. 1855. Rhipiphoridum Coleopterorum familiae dispositio systematica. Berolini, Friderici Nicolai. 36p.

González, U. \& Juárez, G. 2016. Primer registro de Macrosiagon octomaculata (Gerstaecker, 1855) para Perú (Coleoptera: Ripiphoridae). Boletín de la Sociedade Entomológica Aragonesa, 59: 290.

Grandi, G. 1936. Morfologia ed etologia comparata di Insetti a regime specializzato. XII Macrosiagon ferrugineum flabellatum F. Bollettino dell' Istituto di Entomologia dela Universita di Bologna, 9: 33-34.
Heitmans, W.; Heitmans, R.B.; Peeters, T.M.J.; Rond, J. de \& Smit, J. 1994. A survey of the Western European Rhipiphoridae including the first record of a Macrosiagon species in the Netherlands (Coleoptera). Entomologische Berichten, 54(11): 201-211.

Horn, G.H. 1875. Notes on the species of Ripiphorus of the United States. Transactions of the American Entomological Society, 5: 121-125.

Hunt, J.H. 1999. Trait mapping and salience in the evolution of eusocial Vespid wasps. Evolution, 53(1): 225-237.

Jarvis, E. 1922. Early stages of Macrosiagon cucullata MacL. Queensland Agricultural Journal, 17: 307.

Lawrence, J.F.; Falin, Z.H. \& Ślipiński, A. 2010. 11.8 Ripiphoridae Gemminger and Harold, 1870 (Gerstaecker, 1855). In: Leschen, R.A.B.; Beutel, R.G. \& Lawrence, J.F. (Eds.). Coleoptera, Beetles. Vol. 2: Morphology and systematics (Elateroidea, Bostrichiformia, Cucujiformia partim). Berlin, Walter de Gruyter. p. 538-548. (Handbook of Zoology, Arthropoda: Insecta).

LeConte, J.L. 1858. Catalogue of Coleoptera of the region adjacent to the boundary line between the United States and Mexico. Journal of the Academy of Natural Science of Philadelphia, 4(2): 9-42.

Linsley, E.G. \& MacSwain, J.W. 1951. The Rhipiphoridae of California (Coleoptera). Bulletin of the California Insect Survey, 1(3): 79-88.

Linsley, E.G.; MacSwain, J.W. \& Smith, R.F. 1952. The life history and development of Rhipiphorus smithi with notes on their phylogenetic significance (Coleoptera, Rhipiphoridae). University of California Publications in Entomology, 9(4): 291-314.

López-Colón, J.I. 1997. Revisión taxonómica y distribución de Macrosiagon pallidipennis Reitter, 1898 (Coleoptera: Rhipiphoridae). Zapateri Revista Aragonesa de Entomología, 7: 245-250.

Luo, Y.; Wang, L.; Green, L.; Song, K.; Wang, L. \& Smith, R. 2015. Advances of drag-reducing surface technologies in turbulence based on boundary layer control. Journal of Hydrodynamics, 27(4): 473-487. DOI

Majka, C.G.; Chandler, D.S.; Sheffield, C.S. \& Webster, R.P. 2006. New records of Ripiphoridae (Coleoptera) from the Maritime provinces of Canada. The Coleopterists Bulletin, 60(4): 299-303. D0I

Manfrini de Brewer, M. 1966. Subfamilia Ripiphorinae (Col. Ripiphoridae) revision de las especies Argentinas del genero Macrosiagon Hentz. Revista de la Facultad de Ciencias Exactas, Fisicas y Naturales, 27: 5-53.

Matthews, R.W. \& González, J.M. 2004. Nesting biology of Zeta argillaceum (Hymenoptera: Vespidae: Eumeninae) in Southern Florida, U.S. Florida Entomologist, 87(1): 37-40.

Nowell, W. 1915. Two scoliid parasites on scarabaeid larvae in Barbados. Annals of Applied Biology, 2(1): 46-57.

Pinto, J.D. 2003. Hypermetamorphosis. In: Resh, V.H. \& Cardé, R.T. (Eds.). Encyclopedia of Insects. New York, Academic Press. p. 546-549.

Pohl, H. 2002. Phylogeny of the Strepsiptera based on morphological data of the first instar larvae. Zoologica Scripta, 31: 123-134.

Pohl, H. \& Beutel, R.G. 2004. Fine structure of adhesive devices of Strepsiptera (Insecta). Arthropod Structure \& Development, 33: 31-43.

Pohl, H. \& R.G. Beutel. 2008. The evolution of Strepsiptera (Hexapoda). Zoology, Jena, 111(4): 318-338.

Poole, R.W. \& Gentili, P. 1996. Nomina Insecta Nearctica: a check list of the insects of North America. Volume 1: Coleoptera, Strepsiptera. Rockville, Entomological Information Services. 827p.

Razzak, M.A. 2018. Drag reduction using microcavity on flat surface. In: Offshore Technology Conference. Proceedings. Kuala Lumpur, Malasia, 2018. 6p. (0TC - 28482 - MS).

Riley, C.V. 1874. The unadorned Tiphia, or white grub parasite - Tiphia iiwniata Say. Annual report Institut of Missouri, 60. p. 123-126.

Rivnay, E. 1929. Revision of the Rhipiphoridae of North and Central America (Coleoptera). Memoirs of the American Entomological Society, 6: 1-68. 
Robertson, C. 1924. Flowers and Insects XXIII. Botanical Gazette, 78(1): 68-84.

Roubaud, E. 1910. Recherches sur la Biologie des Synagris. Évolution de l'instinct chez les Guêpes Solitaires. Annales de la Société Entomologique de France, 79: 1-21.

Rozen, J.G. 1997. New taxa of brachynomadine bees (Apidae: Nomadinae). American Museum Novitates, 3200: 1-26.

Sánchez Rodríguez, J.L. 2001. Contribución al conocimiento de los Rhipiphoridae (Coleoptera) en Andalucía. Boletín de la Sociedad Andaluza de Entomología, 2: 29-32.

Sano, P.T. 2001. Actinocephalus (Körn.) Sano (Paepalanthus sect. Actinocephalus), a new genus of Eriocaulaceae, and other taxonomic and nomenclatural changes involving Paepalanthus Mart. Taxon, 53(1): 99-107.

Scherer, K.Z. \& Castellani, T.T. 2004. Ecologia populacional de Paepalanthus polyanthus (Bong.) Kunth: variação temporal da distribuição espacial. Biotemas, 17(2): 27-45.

Selander, R.B. 1991a. Rhipiphoridae (Tenebrionoidea). In: Stehr, F.W. (Ed.). Immature Insects. lowa, Kendall/Hunt Publ.Co. v. 2, p. 509-512.

Selander, R.B. 1991b. Meloidae (Tenebrionoidea). In: Stehr, F.W. (Ed.). Immature Insects. lowa, Kendall/Hunt Publ.Co. v. 2, p. 530-535.

Silvestri, F. 1906. Descrizione di un nuovo genere di Rhipiphoridae. Redia Giornale di Entomologia, 3: 315-324 + pl. XX.
Smith, T.J.R. 1971. Field notes on the occurrence of Hemithynnus hyalinatus (Hymenoptera: Tiphiidae) as a parasite of Scarabaeids on the New England Tablelands. Journal of the Australian Entomological Society, 10: 265-270.

Snelling, R.R. 1963: A host of Macrosaigon [sic!] cruentum (Genmar) [sic!] in Georgia. Pan-Pacific Entomologist, 39: 87-88.

Švácha, P. 1994. Bionomics, behaviour and immature stages of Pelecotoma fennica (Paykull) (Coleoptera: Rhipiphoridae). Journal of Natural History, 28(3): 585-618.

Tomlin, A.D. \& J.J. Miller. 1989. Physical and Behavioral Factors Governing the Pattern and Distribution of Rhipiphoridae (Coleoptera) Attached to Wings of Halictidae. Annals of the Entomological Society of America, 82(6): 785-791.

Vaurie, P. 1955. A review of the genus Macrosiagon in Mexico, with notes on Rhipiphorus (Coleoptera, Rhipiphoridae). American Museum Novitates, 1717: 1-19.

Verdugo, A. 2010. Segundo registro de Macrosiagon ferruginea (Fabricius, 1775) para la provincia de Cádiz (España) (Coleoptera, Ripiphoridae). Revista Gaditana de Entomología, 1(1): 24-26.

Yamane, S. 1990. A revision of the Japanese Eumenidae (Hymenoptera, Vespoidea). Insecta Matsumurana, 43: 1-189. 